\title{
Experimental Research on Mechanical Properties and Microstructure Characteristics of Silty Clay Subgrade Filler With Red Pisha Sandstone and Carbide Slag in Seasonal Frozen Regions
}

\author{
Yuhang Liu \\ Dongqing Li \\ Northwest Institute of Eco-Environment and Resources \\ Feng Ming ( $\sim$ mingfeng05@lzb.ac.cn) \\ Northwest Institute of Eco-Environment and Resources
}

Northwest Institute of Eco-Environment and Resources https://orcid.org/0000-0002-6580-2958

\section{Research Article}

Keywords: Red Pisha sandstone, carbide slag, silty clay stabilization, mechanical property, microstructure Posted Date: November 30th, 2021

DOI: https://doi.org/10.21203/rs.3.rs-1022748/v1

License: (c) (i) This work is licensed under a Creative Commons Attribution 4.0 International License.

Read Full License 


\section{Abstract}

As the foundation structure of highway engineering, the quality of the subgrade determines the service life of highway engineering. Under this condition, the filling soils are frequently improved for raising the stability of the subgrade. Proper utilization of lower-cost waste materials will reduce demand for natural materials and the cost of construction. In this study, the red Pisha sandstone (RPS) and carbide slag (CS) as green and sustainable materials to reinforce the silty clay. The improvement effect was evaluated through freeze-thaw cycles test, triaxial compression strength test, particle-size distribution test, X-ray diffraction test, and scanning electron microscopy test. The results indicated that the addition of $15 \mathrm{wt} . \%$ RPS and $15 \mathrm{wt} . \%$ CS increased about $136 \%$ of the triaxial compressive strength of silty clay. With the increase of freeze-thaw cycles, the strength loss ratio and the deformation change slightly. It also has the excellent function of freezing and thawing resistance and shear strength. The key factors for the superior mechanical performance of RPS-CS stabilized silty clay are that more sand-size particles are beneficial to the hydration reactions of RPS and CS during the entire curing time, adequate flocculation and agglomeration of soil particles occurred. Many small-sized rounded and plate-like CSH gels filled most of the soils pores and isolated pores fractures became fewer in the samples, which produced a denser and less permeable material. The outcomes of this research will contribute to the utilization of red Pisha sandstone and carbide slag as a sustainable stabilizer in highway subgrade applications in seasonal frozen regions.

\section{Introduction}

The area of the seasonal frozen soil is about $51,370,000 \mathrm{~km}^{2}$, which accounts for approximately $53.5 \%$ of China's land area (Zhou, Ma et al. 2018, Chen, Guo et al. 2020). Many engineering projects, such as dams, highways, and railway oil pipelines, have been built in seasonal frozen regions due to the development of the economy and the utilization of energy and natural resources. However, the physical and mechanical properties of subgrade soils will deteriorate due to the freeze-thaw cycles, which leads to more engineering problems (Chen, Guo et al. 2020, Du, Liu et al. 2021). With the implementation of "The Belt and Road Initiative" strategy, the density of the traffic network will be gradually increased and the traffic volume increases continuously. More and more engineering projects have been built in regions that lack natural and high-quality soils. Thus, to extend the service time of the subgrade and reduce construction costs, the filling soils are frequently strengthened by different improved methods.

At present, in order to change low bearing capacity, many ameliorative measures have been applied to strengthen the soil properties. Chemical stabilization is an effective method to improve the engineering properties of silty clay (Dong and Wang 2019), and a lot of industrial by-products have been treated as low-carbon and less energy intensive materials and are widely used in civil engineering (Cai, Du et al. 2015, Yi, Gu et al. 2016, Maria, Farhan et al. 2021). This is because large quantities of industrial waste materials are usually piled outside factories or landfilled in some designated areas (Mmada, Amrb et al. 2021). A large amount of soil is occupied and environmental pollution is caused. Meanwhile, their storage involves difficulties in terms of long-term stability. Thus, a large number of scholars utilized 
industrial waste materials to produce sustainable building materials for reducing the harmful impact on people and the environment and save costs (Yi, Zheng et al. 2015, Ruan and Unluer 2016, Singh and Subramaniam 2019, Zhang, Sojobi et al. 2019).

Carbide slag (CS) is an industrial by-product which widely used to improve the material properties of soil (soft soil, silty soil, saline soil, and expansive soil, etc.) of subgrade (Cardoso, Fernandes et al. 2009). Researchers pointed out that carbide slag is better than other materials (fly ash and quick lime) in improving the swelling property of expansive soil (Zhang, Lv et al. 2019). CS can be used as an alternative stabilizer of quick lime or other materials in highway subgrade applications (Jiang, Du et al. 2015). This is mainly because that carbide slag has a finer particle size, greater specific surface area, and higher $\mathrm{pH}$ value than others. The soil particle flocculation and agglomeration at the early stage and pozzolanic reactions during the entire curing time are more adequate. As a result, the mechanical strength of CS-stabilized soils has significantly increased. A few studies indicated that CS, as industry waste, has more economic and environmental benefits compared to MgO (Jiang, Du et al. 2015, Yi, Zheng et al. 2015). It can be seen that highway subgrade construction has been identified as an avenue to consume huge quantities of CS as a chemical additive for soil stabilization. According to statistics, about 90 to 114 tons of carbide slag was produced in China every year. A large number of areas were used to store these industrial wastes (Yi, Gu et al. 2016). To expand its use scope, the storage of carbide slag can be decrease and the negative environmental impacts can also be reduced.

The red Pisha sandstone (RPS) is a sediment source of the Yellow River, which is composed of amorphous clay minerals and crystalline minerals. It is widely distributed in northwestern China with an area of more than $16,700 \mathrm{~km}^{2}$. The bonded mechanism of RPS was bad and it has an unsatisfactory petrographic structure, it is very hard like the rock when it is dry. However, it would collapse into sand quickly when it is immersed in water due to the expansion of soggy clay minerals. Thus, its special structural characteristics caused environmental damage such as land desertification and soil erosion. In order to control these phenomena, the research of RPS has focused on improving its weak native structure and reducing the weathering rate after exposure to water (Liang, Yang et al. 2016, Li, Dong et al. 2018). In recent years, some studies focus on the recycling use of RPS has been conducted because this material has the advantage of large storage and price moderate (Su, Zhang et al. 2013, Wang, Deng et al. 2020). The soft rock and sand compound soil technique greatly reduces the phenomenon that the generates soil erosion and wasting of resources $\square$ Researchers studied the soil quality development status of a new type of mixed composite soil of soft rock and sand in the Mu Su sandy land during the longterm planting process (Zhang, Guo et al. 2021). They found that the particle size of Pisha sandstone and aeolian sand soil are complementary, and Pisha sandstone can be used as a natural material to restore sandy land into cultivated land. In addition, some scholars suggested that the RPS is a potential alternative material with a better improvement effect than standard sand in geotechnical applications ( $\mathrm{Li}$, Zhang et al. 2016, Li, Dong et al. 2018, Dong, Li et al. 2019). They found that natural RPS can partly dissolve in alkali solutions $(\mathrm{NaOH})$, in which the active $\mathrm{SiO}_{2}$ and $\mathrm{Al}_{2} \mathrm{O}_{3}$ in natural RPS form geopolymers. But the rate of dissolution of active $\mathrm{SiO}_{2}$ and $\mathrm{Al}_{2} \mathrm{O}_{3}$ is insufficient to produce a binder with high strength. 
The addition of blast furnace slag or fly ash results in the formation of a large number of geopolymers and hydration products in RPS, thus the strength is increased (Sivasakthi, Jeyalakshmi et al. 2021). Gradually, some low-cost supplementary cementitious materials and geopolymers cement can be developed in natural red Pisha Sandstone for realized the resource utilization of RPS. Thus, it may be a beneficial exploration to apply RPS in improving subgrade soil as an ameliorating material. However, there have been few studies focusing on the improvement of silty clay with RPS and some inorganic compound materials (cement, lime, and industrial wastes, etc.).

To expand the usage degree of RPS, industrial waste residue, and reduce the subgrade disease, this study investigates the utilization of RPS, CS, and RPS-CS blends for silty clay stabilization in the seasonal frozen regions. A series of tests, including freeze-thaw cycles test, triaxial compression strength (TCS) test, particle size distribution (PSD) test, $\mathrm{X}$-ray diffraction (XRD) test, and scanning electron microscopy (SEM) test, were conducted in the laboratory. Subsequently, the properties of the improved silty clay were analyzed comprehensively from the physical, chemical, and microstructure aspects. The goal of this study is to enhance the sustainable utilization degree of red Pisha sandstone and carbide slag and reduction in demand for natural high-quality soils and the cost of construction.

\section{Materials And Methods}

\subsection{Material properties}

\subsubsection{Silty clay}

The silty clay, which was obtained from a highway construction field in Lanzhou, China, was used in this study (Fig. 1). The basic physical and engineering properties of the soil are listed in Table 1. The PSD curve of the silty clay is shown in Fig. 2. The main chemical properties are shown in Fig. 3. 
Table 1

Physical parameters of silty clay

\begin{tabular}{|ll|}
\hline Property & Value \\
\hline Liquid limit, $w_{\mathrm{L}}(\%)$ & 28.35 \\
\hline Plastic limit, $w_{\mathrm{P}}(\%)$ & 13.04 \\
\hline Maximum dry density, $\rho_{\mathrm{d}, \mathrm{max}}\left(\mathrm{g} / \mathrm{cm}^{3}\right)$ & 1.78 \\
\hline Optimum moisture content, $w_{\mathrm{opt}}(\%)$ & 16.16 \\
\hline Specific surface area $\left(\mathrm{m}^{2} / \mathrm{g}\right)$ & 11.46 \\
\hline Particle-size distribution $(\%)$ & \\
\hline Clay $(<2 \mu \mathrm{m})$ & 4.77 \\
\hline Silt $(2 \mu \mathrm{m}$ to $74 \mu \mathrm{m})$ & 92.35 \\
\hline Sand $(>74 \mu \mathrm{m})$ & 2.88 \\
\hline
\end{tabular}

\subsubsection{Red Pisha sandstone and carbide slag}

The Rad Pisha sandstone (RPS) and carbide slag (CS) were collected from Yanglin City, Shaanxi Province, China (Fig. 1). Their basic physical characteristics were listed in Table 2. The PSD curves of RPS and CS are shown in Fig. 4. The maximum particle size of red Pisha sandstone is within the range of 400-600 $\mu \mathrm{m}$ and carbide slag is 50-100 $\mu \mathrm{m}$. The main chemical properties are shown in Fig. 5.

Table 2

Basic physical properties of RPS and CS

\begin{tabular}{|lll|}
\hline Property & RPS & CS \\
\hline Specific surface area $\left(\mathrm{m}^{2} / \mathrm{g}\right)$ & 3.39 & 10.30 \\
\hline Particle-size distribution $(\%)$ & & \\
\hline Clay $(<0.002 \mathrm{~mm})$ & 0 & 2.19 \\
\hline Silt $(0.002 \mathrm{~mm}$ to $0.074 \mathrm{~mm})$ & 6.50 & 62.76 \\
\hline Sand $(>0.074 \mathrm{~mm})$ & 93.50 & 35.05 \\
\hline
\end{tabular}

\subsection{Sample preparation}

The admixtures and dry silty clay were mixed firstly, and then the required water was added. The mix proportions of the mixture were listed in Table 3. For all the samples, the ratio of water was kept at a constant value of $16 \%$. The samples were prepared as cylinders with $39.1 \mathrm{~mm}$ in diameter and $80.0 \mathrm{~mm}$ 
in height. After being removed from the molds, three samples for each formulation were wrapped and insulated in plastic bags to prevent them from evaporation. All prepared samples were subsequently cured at $20^{\circ} \mathrm{C} \pm 2^{\circ} \mathrm{C}$ and relative humidity of $95 \% \pm 3 \%$ for 7 days before testing.

Table 3

Mix proportion of mixture (wt.\%)

\begin{tabular}{|c|c|c|c|c|c|}
\hline & \\
\hline \multirow[t]{2}{*}{ Group } & \multirow[t]{2}{*}{ Type } & \multicolumn{3}{|c|}{ Solid Powder Mix proportions } & \multirow[t]{2}{*}{$\mathrm{s} / \mathrm{b}^{\#}$} \\
\hline & & S & RPS & CS & \\
\hline A & $A$ & 100 & 0 & 0 & \multirow[t]{12}{*}{0.16} \\
\hline \multirow[t]{3}{*}{ B } & B1 & 90 & 10 & 0 & \\
\hline & B2 & 85 & 15 & 0 & \\
\hline & B3 & 80 & 20 & 0 & \\
\hline \multirow[t]{3}{*}{ C } & $\mathrm{C} 1$ & 90 & 0 & 10 & \\
\hline & $\mathrm{C} 2$ & 85 & 0 & 15 & \\
\hline & C3 & 80 & 0 & 20 & \\
\hline \multirow[t]{2}{*}{ D } & D1 & 85 & 10 & 5 & \\
\hline & $\mathrm{D} 2$ & 80 & 10 & 10 & \\
\hline \multirow[t]{3}{*}{ E } & E1 & 80 & 15 & 5 & \\
\hline & E2 & 75 & 15 & 10 & \\
\hline & E3 & 70 & 15 & 15 & \\
\hline
\end{tabular}

\subsection{Freeze-thaw cycles test}

The soil samples with good mechanical properties were selected for the following freeze-thaw cycles test. The samples were put in a temperature-control environmental box (temperature accuracy is $\pm 0.5^{\circ} \mathrm{C}$ ). According to previous work (Qu, Ni et al. 2020), the samples were frozen at $-20^{\circ} \mathrm{C}$ for $12 \mathrm{~h}$ and thawed at $20^{\circ} \mathrm{C}$ for $12 \mathrm{~h}$. The freeze-thaw procedure was conducted in a closed system without water supply. The soil samples experienced different cycle numbers of $0,5,10,15$, and 20.

\subsection{Experimental method}

\subsubsection{Triaxial compression strength test (TCS)}

All triaxial tests were performed by applying the GDS unsaturated soil triaxial system (Fig. 6). Referred to the previous experience, a constant axial displacement rate of $0.4 \mathrm{~mm} / \mathrm{min}$ was adopted. The confining pressure of all the triaxial tests was controlled as $100 \mathrm{kPa}, 200 \mathrm{kPa}$, and $400 \mathrm{kPa}$, respectively. During the tests, load and deformation data were recorded and stored by the data acquisition system. After the axial deformation reached $15 \%$, the test was stopped. 


\subsubsection{Particle-size distribution test (PSD)}

PSD tests were conducted using a Mastersizer 2000 laser particle-size analyzer after freeze-thaw cycles. Prior to PSD analysis, all soil specimens were air-dried and grinded through a $0.075 \mathrm{~mm}$ sieve. Then, a $15 \mathrm{~g}$ grinded specimen was mixed with sufficient distilled water and subjected to the PSD analysis.

\subsubsection{X-ray diffraction test (XRD)}

XRD tests are carried to examine the chemical composition of the raw materials and the samples after the triaxial test and freeze-thaw test by a German Bruker D8 instrument. A Cu-Ka X-ray tube with an input voltage of $40 \mathrm{kV}$ and a current of $40 \mathrm{~mA}$ was utilized. Prior to the test, both these soil specimens were dried and then grinded into a sieve with $0.038 \mathrm{~mm}$. The XRD spectra were carried out between $2 \theta$ range of $5^{\circ}$ and $90^{\circ}$ at a scan rate of $2^{\circ} / \mathrm{min}$. A step size of $0.02^{\circ}$ was used.

\subsubsection{Scanning electron microscope test (SEM)}

The microstructure of samples (after freeze-thaw cycles) was observed by a Quanta FEG450 scanning electron microscope at an accelerating voltage of $20 \mathrm{kV}$. And the chemical elementals analyses were performed by an energy dispersive X-ray spectroscope device equipped with this SEM system. In particular, all samples in the experiment were dried and sprayed with gold, and the microscopic images needed for analysis were obtained by scanning electron microscopy.

\section{Results And Discussion}

\subsection{Macroscopic mechanical characteristics}

\subsubsection{Stress-strain response of triaxial compression test}

(a) Influence of admixtures on the stress-strain curves

The stress-strain types of the soil samples with different confining pressures and admixtures volume fractions are presented in Fig. 7. It can be seen that these samples behave as softening and plastic characteristics in the presence of confining pressure. The plastic behavior is reflected in Group $A$ and Group B samples. The softening characteristic is observed particularly in the Group C samples. This softening characteristic is present slightly in the Group D and Group E samples. For higher confining pressure $(400 \mathrm{kPa})$, these samples have a tendency to develop with plastic characteristics. One important reason is that with the increase of confining pressure, the inhibiting function on the radial deformation of the sample is enhanced, which directly causes to the transformation of the curve feature (Farnam, Moosavi et al. 2010).

For Fig. 7(b), at any volume fraction of red Pisha sandstone content, the plastic behaviors of Group B samples are not changed compared with sample A. According to Fig.7(c), the softening characteristic showed a significant improvement by increasing carbide slag content. With increasing carbide slag content in a constant red Pisha sandstone content, these plastic behaviors have a tendency 
to change to the softening behaviors in Fig.5 (d) and (e). It is remarkable that a transition from softening to plastic behavior can be predicted between 5 to 10 wt.\% carbide slag in Fig.7 (d).

(b) Strength characteristics

Peak strength versus red Pisha sandstone and carbide slag content of soil samples are plotted in Fig.8 (a). Note that the maximum deviatoric stress observed during the triaxial test on each specimen was recorded as the peak strength in softening behavior curves. And For the plastic behavior curves or hardening behavior curves, the deviatoric stress at $15 \%$ axial strain was determined as the peak strength. As illustrated in the figure, the peak deviatoric stress was influenced by both the content of red Pisha sandstone and carbide slag. To analyze the overall trend of strength change, the strength change ratio $a$ is introduced:

$$
\alpha=\frac{q_{\mathrm{i}}-q_{\mathrm{A}}}{q_{\mathrm{A}}}
$$

Where $q_{\mathrm{i}}$ is the peak strength of Group B to Group E samples; $q_{\mathrm{A}}$ is the peak strength of sample A.

In Fig.8 (b), the relationship between strength change ratio and admixtures and volume fractions is shown. For Group B samples, by increasing red Pisha sandstone content in a constant confining pressure condition, the strengths no obvious change. Only adding red Pisha sandstone up to $15 \mathrm{wt}$ \% volume fraction of silt clay is even smaller than the strength of the plain silt clay. For the Group $\mathrm{C}$ samples which are containing only carbide slag, the strengths increase obviously with the increase of carbide slag volume. Take the sample with the confining pressure of $200 \mathrm{kPa}$ as an example, the strengths of the samples in Group C are increased by about $124 \%, 143 \%$, and $189 \%$ compared with sample A, respectively. When carbide slag and red Pisha sandstone are mixed into the soil at the same time, the peak strength of sample E3 is best. The strength change ratio is $136 \%$ under $200 \mathrm{kPa}$ confining pressure.

Failure patterns of these samples under the triaxial compression test are shown in Fig.9. Since the failure modes were approximately similar in all the confining pressure ranges, the pictures for the $200 \mathrm{kPa}$ confining pressure test are depicted. As shown in this figure, sample A (plain silty clay) and Group B samples are plastic deformations. The deformation of group $B$ samples is slightly less than that of sample A. The Group $C$ samples are obviously brittle deformation. The shear failures were observed on a distinguished diagonal plane above the soil samples. And these samples also show other multiple shear cracks during loading. With the increase of the content of carbide slag (from 10wt.\% to $20 \mathrm{wt} . \%$ ), the failure mode becomes more obvious. In addition, no obvious shear failure surface was formed on Group $D$ and Group E samples, and there was a slight bulge and shear in the middle of the samples. This indicates that adding red Pisha sandstone may lead to a more ductile behavior and seems to be sufficient to prevent crack propagation and lateral expansion. As a result, the failure mode of these samples is changed from brittle failure mode to plastic failure mode. 
From what has been discussed above, it is clearly found that the red Pisha sandstone plays a less significant role in triaxial properties with increasing confining pressure to RPS-stabilized soil. There is little change in strength and deformation. For CS-stabilized silty clays, an increase in volume fraction of carbide slag increases to strength in soil. However, the deformation which showed a distinguished diagonal plane and multiple shear cracks were obviously aggravated. For RPS-CS stabilized silty clays, the strength was increased and a combination of shear and bulge mode of failure was observed. Meanwhile, the degree of deformation does not vary much.

Therefore, it can be considered that the samples of CS-stabilized silty clay (C1,10wt.\% CS) and RPS-CS stabilized silty clay (E3, 15wt.\% RPS and 15wt.\% CS) have a better improvement effect. In the following, only these specimens were subjected to freeze-thaw cycles test, PSD test, XRD test, and SEM test.

\subsubsection{The ability of freezing and thawing resistance (C1 and E3)}

(a) Influence of freeze-thaw cycles on strength characteristics

Triaxial compression results of C1 (CS-stabilized silty clay) and E3 (RPS-CS stabilized silty clay) under different freeze-thaw cycles and confining pressure conditions are shown in Fig.10. The confining pressure has little effect on the curve type, and all of them show softening behavior. The freeze-thaw cycles' have an obvious effect on the stress-strain behavior. For CS-stabilized silty clays, the peak deviatoric points gradually move to the right with the increase of freeze-thaw cycles. However, the number of freeze-thaw cycles has a slight effect on the residual stress. The characteristics of RPS-CS stabilized silty clays are basically opposite to those of CS-stabilized silty clays. The peak points did not move with the increase of freeze-thaw cycles. The residual stress decrease with the increase of freeze-thaw cycles under $100 \mathrm{kPa}$ confining pressure. When the confining pressure values are $200 \mathrm{kPa}$ and $400 \mathrm{kPa}$, the residual stresses are basically the same values under freeze-thaw cycles $\leq 10$. The residual stresses have a tendency to decrease under freeze-thaw cycles $\otimes 10$. Thus, it can be considered that the 5 freeze-thaw cycles are the critical value of soil stability for RPS-CS stabilized silty clay.

The variation of the peak strength with the confining pressure under different freeze-thaw conditions is summarized in Fig. 11(a). It can be seen that the peak strength of CS-stabilized silty clays tends to decrease with increasing freeze-thaw cycles; while the freeze-thaw cycles have little influence on the peak strength of RPS-CS stabilized silty clays. Comparing with the lower confining pressure, the sample at higher confining pressure has a larger loss on the peak strength. Fig.11(b) shows the relationship between the strength loss ratio and the freeze-thaw cycles, respectively. The maximum strength loss ratio of CS-stabilized silty clays is 0.137 under the confining pressure of $400 \mathrm{kPa}$, the freeze-thaw cycles of 20 . The minimum strength loss ratio is 0.018 under the confining pressure of $100 \mathrm{kPa}$, the freeze-thaw cycles of 5. The maximum strength loss ratio of RPS-CS stabilized silty clays is 0.047 under the $100 \mathrm{kPa}$ confining pressure, the 15 freeze-thaw cycles. The minimum strength loss ratio is 0.004 under the 400 $\mathrm{kPa}$ confining pressure, the 5 freeze-thaw cycles. On the whole, the strength loss ratio of CS-stabilized silty clays is greater than that of RPS-CS stabilized silty clays. 
Since the failure modes were approximately similar in all the confining pressure ranges, failure patterns of CS-stabilized silty clays and RPS-CS stabilized silty clays under the $200 \mathrm{kPa}$ confining pressure test are depicted in Fig.12. For CS-stabilized silty clays, shear failure was observed on a diagonal plane which is typical of the brittle materials at the top of the figure. After freeze-thaw cycles, the shear plane angle of the sample decreases, but the distinguished shear plane is still obvious. And these samples also show other multiple shear cracks during the freeze-thaw process. For RPS-CS stabilized silty clays, the failure mechanism is bulging and shearing at the bottom of the picture. And all shear planes are smaller than those of CS-stabilized silty clays. Therefore, it is clearly found that the RPS-CS stabilized silty clays have smaller deformation during the freeze-thaw process.

\subsubsection{Shear indexes}

According to the Mohr-coulomb theory, the internal friction angle $(j)$ and cohesive force $(c)$ of these samples are calculated, as presented in Fig.13. It can be seen that with the increase of freeze-thaw cycles, the internal friction angle of CS-stabilized silty clays decreases gradually (from $35^{\circ}$ to $30^{\circ}$ ), while the internal friction angle of RPS-CS stabilized silty clays has little change. This suggests that the effect of freeze-thaw cycles on the internal friction angle of CS-stabilized silty clays is more obvious. It is known from the cohesive force of RPS-CS stabilized silty clays gradually decreases with the increase of freezethaw cycles. The cohesive force of CS-stabilized silty clays shows a trend of decreasing first and then increasing. And, the change range of cohesion force of RPS-CS stabilized silty clays is smaller.

With the view of the quantitative point, the conclusion that the freeze-thaw cycles have a greater effect on cohesive force and internal friction angle of CS-stabilized silty clays than that of RPS-CS stabilized silty clays is verified again ( $\mathrm{Li}$, Li et al. 2018). This further explains the deformation of RPS-CS stabilized silty clays is less than CS-stabilized silty clays after multiple freeze-thaw cycles, combined with Fig. 12.

\subsection{Microscopic reinforcement mechanism}

\subsubsection{PSD test results}

(a) Variation of particle size distribution

Fig.14 presents the particle size gradation curves for CS-stabilized silty clays and RPS-CS stabilized silty clays under different freeze-thaw cycles, respectively. It can be summarized that during the freeze-thaw cycle process, the particle size becomes small.

At presented, in Fig.14(a), a larger peak exists in the $50 \mathrm{~mm}-100 \mathrm{~mm}$ and a smaller peak exists in the $200 \mathrm{~mm}-500 \mathrm{~mm}$ for CS-stabilized silty clay without freeze-thaw cycle. The first peak moves to the left and decreases under 5 freeze-thaw cycles. And the second wave peak also decreases, but there is basically no moved leftward and rightward. When the freeze-thaw cycle is more than 10 times, the first peak starts to increase and the second peak gradually disappears. Eventually, there is only one peak on each of the curves. Fig.14(b) and Table 4 shows that for RPS-CS stabilized silty clay without freeze-thaw cycle, two obvious peaks appear on the curve in the particle size range of $50 \mathrm{~mm}-100 \mathrm{~mm}$ and $400 \mathrm{~mm}$ 
$-600 \mathrm{~mm}$, respectively. The first peaks gradually increase and the second peaks gradually disappear with the increase of freeze-thaw cycles. At the same time, these peaks do not shift from side to side.

Ultimately, the clay-sized particle percentage increased from $0.607 \%$ to $2.715 \%$ for CS-stabilized silty clay, which is higher than those of RPS-CS stabilized silty clay (from $1.027 \%$ to $0.607 \%$ ) after 20 freeze-thaw cycles. The silt-sized particle percentage increases substantially from $48.176 \%$ to $61.974 \%$ and from $39.152 \%$ to $58.127 \%$, respectively. And RPS-CS stabilized silty clay has more sand-size particles than CSstabilized silty clay.

Some experts believed that the short-term flocculation formation and long-term pozzolanic reactions result in changes in clay-sized and sand-sized particle percentages in the stabilized soils (Tran, Cui et al. 2014). The flocculation contributes to the agglomeration of fine particles and the synthesized pozzolanic products would coat the surface of soil particles, both making a relatively high fraction of coarse-grained particles (Kampala, Horpibulsuk et al. 2013, Tran, Cui et al. 2014, Jiang, Du et al. 2015).

Table 4 Results of PSD test.

\begin{tabular}{|lllll|}
\hline Soil & $\begin{array}{l}\text { Freeze-Thaw } \\
\text { cycles }\end{array}$ & $\begin{array}{l}\text { Clay-sized particle } \\
(<2 \mathrm{~mm})(\%)\end{array}$ & $\begin{array}{l}\text { Silt-sized particle } \\
(2 \mathrm{~mm} \text { to } 74 \mathrm{~mm})(\%)\end{array}$ & $\begin{array}{l}\text { Sand-sized particle } \\
(>74 \mathrm{~mm})(\%)\end{array}$ \\
\hline C1 & 0 & 0.607 & 48.176 & 51.217 \\
& 5 & 2.511 & 58.611 & 38.878 \\
\hline 10 & 2.615 & 60.974 & 36.411 \\
\hline 15 & 2.496 & 60.790 & 36.714 \\
\hline 20 & 2.715 & 61.974 & 35.311 \\
\hline E3 & 1.027 & 39.152 & 59.821 \\
\hline 5 & 1.724 & 49.145 & 49.131 \\
\hline 10 & 1.767 & 51.901 & 46.332 \\
\hline 15 & 1.110 & 54.283 & 44.607 \\
\hline 20 & 0.617 & 58.127 & 41.256 \\
\hline
\end{tabular}

(b) Grading coefficient

The grading coefficients of all samples are shown in Table 5 . When the uniformity coefficient $\left(C_{\mathrm{u}}\right)$ is greater than or equal to 5 , the soil sample is inhomogeneous soil. And when the curvature coefficient $\left(C_{c}\right)$ is in the range of 1 and 3 , the grain size distribution of soil samples is good. It can be seen from the table that the $C_{\mathrm{u}}$ of CS-stabilized silty clays increases at first and then decreases with the increase of freezethaw cycles. The number of freeze-thaw cycles is greater than 10 times, and the $C_{\mathrm{u}}$ basically remains unchanged $(\triangle 5)$ and the non-uniformity is significant. The $C_{\mathrm{C}}$ is in the range of 1 and 1.31 , and the particle size distribution is good. The $C_{\mathrm{u}}$ of RPS-CS stabilized silty clays decreases with the increase of freeze- 
thaw cycles. When freeze-thaw is greater than 10 times, the particles are relatively uniform $\left(C_{\mathrm{u}} \otimes 5\right)$. The $C_{\mathrm{c}}$ is in the range of 1 and 1.13, and the particle grading is a little worse than that of CS-stabilized silty clay.

Table 5 Grading coefficients of samples

\begin{tabular}{|c|c|c|c|c|c|c|c|}
\hline \multirow[t]{2}{*}{ Soil } & \multirow{2}{*}{$\begin{array}{l}\text { Freeze-thaw } \\
\text { cycles }\end{array}$} & \multicolumn{4}{|c|}{ Characteristic particle size $(\mathrm{mm})$} & \multicolumn{2}{|c|}{ Grading parameter } \\
\hline & & $D_{10}$ & $D_{30}$ & $D_{50}$ & $D_{60}$ & $C_{\mathrm{u}}$ & $C_{\mathrm{c}}$ \\
\hline \multirow[t]{5}{*}{ C1 } & 0 & 19.969 & 43.613 & 71.262 & 91.882 & 4.634 & 1.021 \\
\hline & 5 & 11.083 & 30.977 & 52.118 & 67.112 & 6.055 & 1.290 \\
\hline & 10 & 11.260 & 30.101 & 48.826 & 61.606 & 5.471 & 1.296 \\
\hline & 15 & 11.617 & 30.751 & 50.181 & 63.566 & 5.472 & 1.281 \\
\hline & 20 & 11.260 & 30.101 & 48.826 & 61.606 & 5.471 & 1.306 \\
\hline \multirow[t]{5}{*}{ E3 } & 0 & 20.624 & 49.883 & 98.130 & 150.924 & 7.318 & 1.099 \\
\hline & 5 & 15.701 & 38.814 & 67.453 & 92.920 & 5.918 & 1.033 \\
\hline & 10 & 16.888 & 39.078 & 63.201 & 81.583 & 4.831 & 1.108 \\
\hline & 15 & 16.038 & 37.653 & 60.758 & 77.863 & 4.854 & 1.135 \\
\hline & 20 & 16.018 & 36.962 & 57.264 & 77.687 & 4.850 & 1.098 \\
\hline
\end{tabular}

Note: $D_{10} \square D_{30} \square D_{60}$ are the effective particle sizes corresponding to the cumulative percentage of particle size of $10 \%, 30 \%$, and $60 \% ; C_{\mathrm{u}}$ is the non-uniformity coefficient and $C_{\mathrm{c}}$ is the curvature coefficient.

(c) The relationship between $D_{50}$ and strength

Chen et al. pointed out that the sand-sized particles' content was directly related to strength (Chen, Li et al. 2020). The more sand particles in the samples, the larger the pores are. And more sufficient the chemical reaction of the admixture to improve the soil, the more obvious the effect of improving its strength is. The relationship between strength and particle size under freeze-thaw cycles is shown in Fig. 15. It can be seen that the $D_{50}$ and strength of RPS-CS stabilized silty clays are larger than that of CSstabilized silty clays during the freeze-thaw process. The experimental results are consistent with previous research results. The specimens with more sand-sized particles can provide better pore connectivity, the pozzolanic reaction can reach a higher degree, consequently, this sample has a stronger cementing property between the soil particles. Thus, from the view of particle size distribution, it can be concluded that compared to the CS-stabilized silty clay, the red Pisha sandstone mixed with carbide slag will be yield at higher stress. 
The crystalline phases determined by XRD analysis were shown in Fig.16. Unlike the case in sample A, the annite, albite, clinochlore, and calcite diffraction peaks in CS-stabilized silty clay (C1) without freezethaw cycle became weaker in Fig.16(a). However, new diffraction peaks (biotite, dolomite, kornerupine, ettringite, and portlandite) were observed after the pozzolanic reaction. This indicated that when silty clay was activated by $10 \mathrm{wt} \% \mathrm{CS}$, the structure of some mineral phases, which have poor water erosion resistance and strength, was destroyed to yield active Si and Al. It is noted that when the freeze-thaw cycle is greater than 5 , some minerals (dolomite and ettringite) diffraction peaks disappeared and other diffraction peaks became weaker. In Fig.16(b), when 15wt\% RPS and $15 \mathrm{wt} \%$ CS were used as the mineral additives, RPS-CS stabilized silty clays, did not produce any new diffraction peak after the pozzolanic reaction, compared with RPS-CS stabilized silty clay. But, with the increase of freeze-thaw cycles, the ettringite diffraction peaks do not tend to decrease, unlike CS-stabilized silty clay. Other diffraction peaks do not change with the increase of freeze-thaw cycles. At the same time, it can be seen that calcite is present in these samples. The formation of calcite is attributed to the air exposure of soil during the curing period and subsequent carbonation of CS and hydrated products.

In addition, some experts found that the active Si and Al can generate produced amorphous gels(Kinuthia, Wild et al. 1999, Du, Jiang et al. 2014). This is because the pozzolanic reactions between portlandite $\left(\mathrm{Ca}(\mathrm{OH})_{2}\right)$ and reactive $\mathrm{SiO}_{2}$ and $\mathrm{Al}_{2} \mathrm{O}_{3}$ in the soil matrix are reacted, which can be expressed by the following:

$$
\begin{gathered}
\mathrm{Ca}(\mathrm{OH})_{2}+\mathrm{SiO}_{2}+\mathrm{H}_{2} \mathrm{O} \rightarrow \mathrm{C}-\mathrm{S}-\mathrm{H} \\
\mathrm{Ca}(\mathrm{OH})_{2}+\mathrm{Al}_{2} \mathrm{O}_{3}+\mathrm{H}_{2} \mathrm{O} \rightarrow \mathrm{C}-\mathrm{A}-\mathrm{S}-\mathrm{H}
\end{gathered}
$$

During the pozzolanic reactions, alkaline portlandite is gradually consumed and transformed to less alkaline secondary cementitious products (C-S-H gels and C-A-S-H gels) with good water erosion resistance and high strength. For the CS-stabilized silty clays, formation of C-S-H is detected at $2 \mathrm{q}$ of $21.5^{\circ}, 29.3^{\circ}, 36.2^{\circ}$, and $49.1^{\circ}$. The XRD results of the RPS-CS stabilized silty clays reveals the formation of C-S-H $\left(21.5^{\circ}, 27.5^{\circ}, 28.3^{\circ}, 29.3^{\circ}, 31^{\circ}, 36.2^{\circ}, 49.1^{\circ}\right.$ and $\left.50.9^{\circ}\right)$. As C-S-H is the secondary cementitious product formed in the pozzolanic reactions, the identified peaks of C-S-H and the presence of portlandite in the CS-stabilized silty clay and RPS-CS stabilized silty clay after 20 freeze-thaw cycles confirm the progress of pozzolanic reactions is not completely over.

\subsubsection{SEM results}

The scanning electron microscopy was taken at 15,000 magnifications, as shown in Fig.17 and Fig.18. According to particle distribution characteristics (Fig.14 and Table 4), the ratio of large-size particles in RPS-CS stabilized silty clay is greater than that in CS-stabilized silty clay without freezing and thawing cycle. Thus, the soil particles in CS-stabilized silty clay are easily spotted, which are loosely surrounded and bonded by the CSH gel matrix in Fig. 17a. Meanwhile, the sample had a poor microstructure with many pores. For the RPS-CS stabilized silty clay, CSH gels are only around several large-size soil particles 
in Fig. 18a. The particle shape was irregular and the diamond horn of the particle is prominent. The contact mode between particles is point contact, indicating a very limited hydration reaction occurred. The differences can exist due to the surface area and hydrophilia in CS-stabilized silty clay are stronger than that of RPS-CS stabilized silty clay that it was because the former contains more clay particles (Yi, Gu et al. 2014). The hydration reaction of CS-stabilized silty clay is earlier than that of RPS-CS stabilized silty clay, and the uneven flocculation and agglomeration products are formed in the early curing time.

With the increase of freeze-thaw cycles (from 5 to 20), the contact mode of soil particles and hydration products in CS-stabilized silty clays gradually transition from edge-to-face to face-to-face in Fig.17(b)-17(d). The CSH gels are basically wrapped around the soil particles after 20 freeze-thaw cycles. Apart from the rounded and flocculent $\mathrm{CSH}$ particles, reticular microstructures were displayed in the sample. However, some soil particles could be seen clearly, and the size of the particles was heterogeneous. For the RPS-CS stabilized silty clay, when the freeze-thaw cycle is 5 times, the content of $\mathrm{CSH}$ gels increased and slowly adhered to the surface of soil particles rather than just around the soil particles in Fig.17(b). With the increase of freeze-thaw cycles, large amounts of small-sized rounded and plate-like CSH fill most of the clay pores (Fig.17(c) and Fig.17(d)). After 20 freeze-thaw cycles, the distribution of the gel among the particles seems to be fairly homogeneous. The pores between the soil particles have become mostly filled with gels, which altered the microstructure and produced a denser and less permeable material.

An earlier study showed that CSH gels control the final properties of the binding matrix and the mechanical behavior (shear strength, stiffness, and compressibility) of the stabilized soil (Corrêa-Silva, Miranda et al. 2020). The different microstructure and binding ability of CSH gels might reflect the different strengths of soils. The strength of samples decreases as the CSH gels shape more amorphous and binding ability decreases. Thus, it can be seen that the morphologies of CSH gels in Fig.17e and Fig.18e are different; the former is more dispersed, more amorphous, and less uniform. These may be the reasons why the CS-stabilized silty clay has no advantage in strength over that of the RPS-CS stabilized silty clay after 20 freeze-thaw cycles.

\section{Conclusions}

In this study, silty clay of highway subgrade is improved by using lower-cost sustainable red Pisha sandstone and carbide slag. The improvement effect was compared and analyzed by multi-scale laboratory experiments of physical, mechanical, and microstructural properties. The following conclusions can be drawn:

(1) A study of interrelated effects of admixture volume fraction, confining pressure, strength, and also deformation characteristics shows that the modification effect of CS-stabilized silty clay (10wt.\% CS) and RPS-CS stabilized silty clay (15wt.\% RPS and $15 \mathrm{wt} . \% \mathrm{CS}$ ) are better than others without freeze-thaw cycles. The strength increased by about $124 \%$ and $136 \%$, respectively. 
(2) Through the freeze-thaw test, the strength loss ratio, deformation degree, shear strength, and other parameters of CS-stabilized silty clays and RPS-CS stabilized silty clays were obtained. After 0-20 times freeze-thaw cycles, the range of strength loss ratio is 0.018 to 0.137 for CS-stabilized silty clays and 0.004 to 0.047 for RPS-CS stabilized silty clays. The deformation degree of CS-stabilized silty clays is greater than that of RPS-CS stabilized silty clays. On the whole, the freeze-thaw resistance and shear strength of E3 samples are better than $\mathrm{C} 1$ samples.

(3) RPS-CS stabilized silty clay attains more sand-size particles percentage relative to the CS-stabilized silty clay after 20 freeze-thaw cycles. The particle grading structure of the former is slightly worse than that of the latter. With the view of the particle characteristics, the superior mechanical performances of the RPS-CS stabilized soil over CS-stabilized silty clay are wide pore channels exist in the samples and this structure is more conducive to hydration reaction.

(4) The types of chemical products were similar and the contents were different for these two samples. Their main hydration products are $\mathrm{CSH}$ gel and ettringite. After 20 freeze-thaw cycles, for CS-stabilized silty clay, the rounded, flocculent, and reticular CSH gels are basically wrapped around the soil particles. For RPS-CS stabilized silty clay, large amounts of small-sized rounded and plate-like CSH filled most of the soil pores. The RPS-CS stabilized silty clay attains a denser and less permeable structure.

(5) The use of sediment of the Yellow River and industrial waste residue as building materials is a way of resource conservation and environmental protection. Meanwhile, it not only strength the complex utilization degree of red Pisha sandstone and carbide slag, but also open up a path for exploit of secondary resource and improved properties of subgrade filling soil. In the future, research into the durabilities at long ages of these materials is still needed to provide further and clear insights.

\section{Declarations}

Acknowledgments

This research was supported by the Key Research Program of Frontier Sciences of Chinese Academy of Sciences (Grant No. QYZDY-SSW-DQC015), the National Natural Science Foundation of China (No. 41701060).

Declaration of interests

No conflict of interest exists in the submission of this manuscript, and the manuscript is approved by all authors for publication. I would like to declare on behalf of my co-authors that the work descraibed was original research that has not been published previously, and is not under consideration for publication elsewhere, in whole or in part. All the authors listed have approved the manuscript that is enclosed.

\section{References}


Cai, G. H., Y. J. Du, S. Y. Liu and D. N. Singh (2015).Physical properties, electrical resistivity, and strength characteristics of carbonated silty soil admixed with reactive magnesia. Canadian Geotechnical Journal 52: 150408143425002. https://doi.org/10.1139/cgj-2015-0053.

Cardoso, F. A., H. C. Fernandes, R. G. Pileggi, M. A. Cincotto and V. M. John (2009).Carbide lime and industrial hydrated lime characterization. Powder Technology 195(2): 143-149.

https://doi.org/10.1016/j.powtec.2009.05.017.

Chen, H. E., H. T. Guo, X. Q. Yuan, Y. T. Chen and C. Sun (2020). Effect of Temperature on the Strength Characteristics of Unsaturated Silty Clay in Seasonal Frozen Region. KSCE Journal of Civil Engineering 24(9).https://doi.org/10.1007/s12205-020-1974-1

Chen, Q. S., Y. X. Li, H. L. Xiao, W. Peng and J. W. Zhang (2020). Shear behavior of calcareous sands improved by polyurethane foam adhesive considering effects of particle size distribution. Science Technology and Engineering 20(28): 11718-11724.

Corrêa-Silva, M., T. Miranda, M. Rouainia, N. Araújo and N. Cristelo (2020). Geomechanical behaviour of a soft soil stabilised with alkali-activated blast-furnace slags. Journal of Cleaner Production 267:

122017. https://doi.org/10.1016/j.jclepro.2020.122017.

Dong, J. L., C. M. Li, H. Liu, L. Q. Zhang and L. J.Q. (2019). Investigating the mechanical property and reaction mechanism of geopolymers cement with red Pisha Sandstone. Construction and Building Materials 201: 641-650.https://doi.org/10.1016/j.conbuildmat.2018.12.202.

Dong, Z. B. and P. Wang (2019). Study on stability of high fill embankment with silty clay modified by lime and fly ash. Fly Ash Comprehensive Utilization (01):53-56.

Du, W., Q. T. Liu and R. S. Lin (2021). Effects of toluene-di-isocyanate microcapsules on the frost resistance and self-repairing capability of concrete under freeze-thaw cycles. Journal of Building Engineering.

Du, Y. J., N. J. Jiang, S. Y. Liu, F. Jin, D. N. Singh and A. J. Puppala (2014). Engineering properties and microstructural characteristics of cement-stabilized zinc-contaminated kaolin. Canadian Geotechnical Journal 51(3): 289-302. https://doi.org/10.1139/cgj-2013-0177.

Farnam, Y., M. Moosavi, M. Shekarchi, S. K. Babanajad and A. Bagherzadeh (2010). Behaviour of Slurry Infiltrated Fibre Concrete (SIFCON) under triaxial compression. Cement \& Concrete Research 40(11): 1571-1581. https://doi.org/10.1016/j.cemconres.2010.06.009.

Jiang, N. J., Y. J. Du, S. Liu, M. L. Wei, S. Horpibulsuk and A. Arulrajah (2015). Multi-scale laboratory evaluation of the physical, mechanical, and microstructural properties of soft highway subgrade soil stabilized with calcium carbide residue. Canadian Geotechnical Journal 53: 373383. https://doi.org/10.1139/cgj-2015-0245. 
Kampala, A., S. Horpibulsuk, A. Chinkullijniwat and S. L. Shen (2013). Engineering properties of recycled Calcium Carbide Residue stabilized clay as fill and pavement materials. Construction \& Building Materials 46: 203-210. https://doi.org/10.1016/j.conbuildmat.2013.04.037.

Kinuthia, J. M., S. Wild and G. I. Jones (1999). Effects of monovalent and divalent metal sulphates on consistency and compaction of lime-stabilised kaolinite. Applied Clay Science 14(1/3): $27-$

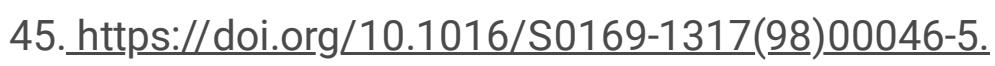

Li, C. M., J. L. Dong, S. B. Zhao, H. Liu, W. Y. Yao and L. J. Wang (2018). Development of low cost supplementary cementitious materials utilizing thermally activated Pisha sandstone. Construction and Building Materials 174: 484-495. https://doi.org/10.1016/j.conbuildmat.2018.04.111.

Li, C. M., T. Zhang and L. Wang (2016). Effect of Dosage of Fly Ash and $\mathrm{NaOH}$ on Properties of Pisha Sandstone-Based Mortar. Aci Materials Journal 113(2): 173-183.

Li, M. Y., X. L. Li, S. H. Chen, Q. Zhang, P. Chang and S. Y. Wu (2018). Experiment study on strength and stress-strain curve characteristic of Pisha-sandstone remolded soil. Journal of Drainage and Irrigation Machinery Engineering 36(02): 179-184. https://doi.org/10.3969/j.issn.1674-8530.16.0315.

Liang, Z. S., C. Q. Yang and Z. R. Wu (2016). Study on Mechanical Properties of Pisha Sandstone Solidified Body with W-OH Composite. Yellow River 38(06): 30-34.

Maria, I., S. Farhan, A. Abreeza and H. Tousif (2021). Improvement in Compressive Strength of StyreneButadiene-Rubber (SBR) Modified Mortars by Using Powder Form and Nanoparticles. Journal of Building Engineering.

Mmada, M., D. Amrb, M. R. Alaa, S. Noha and H. A.A. (2021). An initial study about the effect of activated carbon nano-sheets from residual biomass of olive trees pellets on the properties of alkali-activated slag pastes. Journal of Building Engineering.

Qu, Y. L., W. K. Ni, F. J. Niu, Y. H. Mu and J. Luo (2020). Mechanical and electrical properties of coarsegrained soil affected by cyclic freeze-thaw in high cold regions. Journal of Central South University 27(3): 853-866. https://doi.org/10.1007/s11771-020-4336-8.

Ruan, S. and C. Unluer (2016). Comparative life cycle assessment of reactive $\mathrm{MgO}$ and Portland cement production. Journal of Cleaner Production 137(nov.20): 258-

273. https://doi.org/10.1016/j.jclepro.2016.07.071.

Singh, G. B. and K. Subramaniam (2019). Production and Characterization of Low-Energy Portland Composite Cement from Post-Industrial Waste. Journal of Cleaner Production.

Sivasakthi, M., R. Jeyalakshmi and R. N. P. . (2021). Effect of change in the silica modulus of sodium silicate solution on the microstructure of fly ash geopolymers. Journal of Building Engineering 44. 
Su, T., X. C. Zhang and R. J. Wang (2013). Effect of EN-1 on the shear strength characteristics of Pisha sandstone soildified soil. Farm Machinery 44(09): 86-90+67. https://doi.org/10.6041/j.issn.10001298.2013.09.016.

Tran, T. D., Y. J. Cui, A. M. Tang, M. Audiguier and R. Cojean (2014). Effects of lime treatment on the microstructure and hydraulic conductivity of Héricourt clay. Journal of Rock Mechanics and Geotechnical Engineering 6: 399-404.

Wang, T., L. Deng, L. Y. He, C. Q. Yang and Z. S. Liang (2020). Effect of microbial inoculants on improvement of Pisha sandstone soil. China Environmental Science 40(02): 764-770.

Yi, Y., L. Gu and S. Liu (2014). Microstructural and mechanical properties of marine soft clay stabilized by lime-activated ground granulated blastfurnace slag. Applied Clay Science 103: 71-

76. https://doi.org/10.1016/j.clay.2014.11.005.

Yi, Y., X. Zheng, S. Liu and A. Al-Tabbaa (2015). Comparison of reactive magnesia- and carbide slagactivated ground granulated blastfurnace slag and Portland cement for stabilisation of a natural soil. Applied Clay Science 111(jul.): 21-26. https://doi.org/10.1016/j.clay.2015.03.023.

Yi, Y. L., L. Y. Gu, S. Y. Liu and A. J. Puppala (2016). Carbide slag-activated ground granulated blastfurnace slag for soft clay stabilization. Canadian Geotechnical Journal 52:656-663. https://doi.org/10.1139/cgj-2014-0007.

Zhang, H. O., Z. Guo, Y. Xu, T. T. Cao and C. X. Yang (2021). Dynamic change characteristic of texture and organic matter content of soft rock and sand compound soil in Mu Us sandy land. Research of Soil and Water Conservation 28(02): 93-98.

Zhang, L. W., A. O. Sojobi and K. M. Liew (2019). Sustainable CFRP-reinforced recycled concrete for cleaner eco-friendly construction. Journal of Cleaner Production 233(OCT.1): 5675. https://doi.org/10.1016/j.jclepro.2019.06.025.

Zhang, W. T., Z. G. Lv, R. Wang and H. C. Li (2019). "Wet and dry cycling characteristics of expansive soil stabilized with fly ash and calcium carbide residues." Shanxi Architecture 45(21): 61-63.

Zhou, Z. W., W. Ma, S. J. Zhang, Y. H. Mu and G. Y. Li (2018). "Effect of freeze-thaw cycles in mechanical behaviors of frozen loess." Cold Regions Science \& Technology 146: 9-

18. https://doi.org/10.1016/j.coldregions.2017.11.011.

\section{Figures}




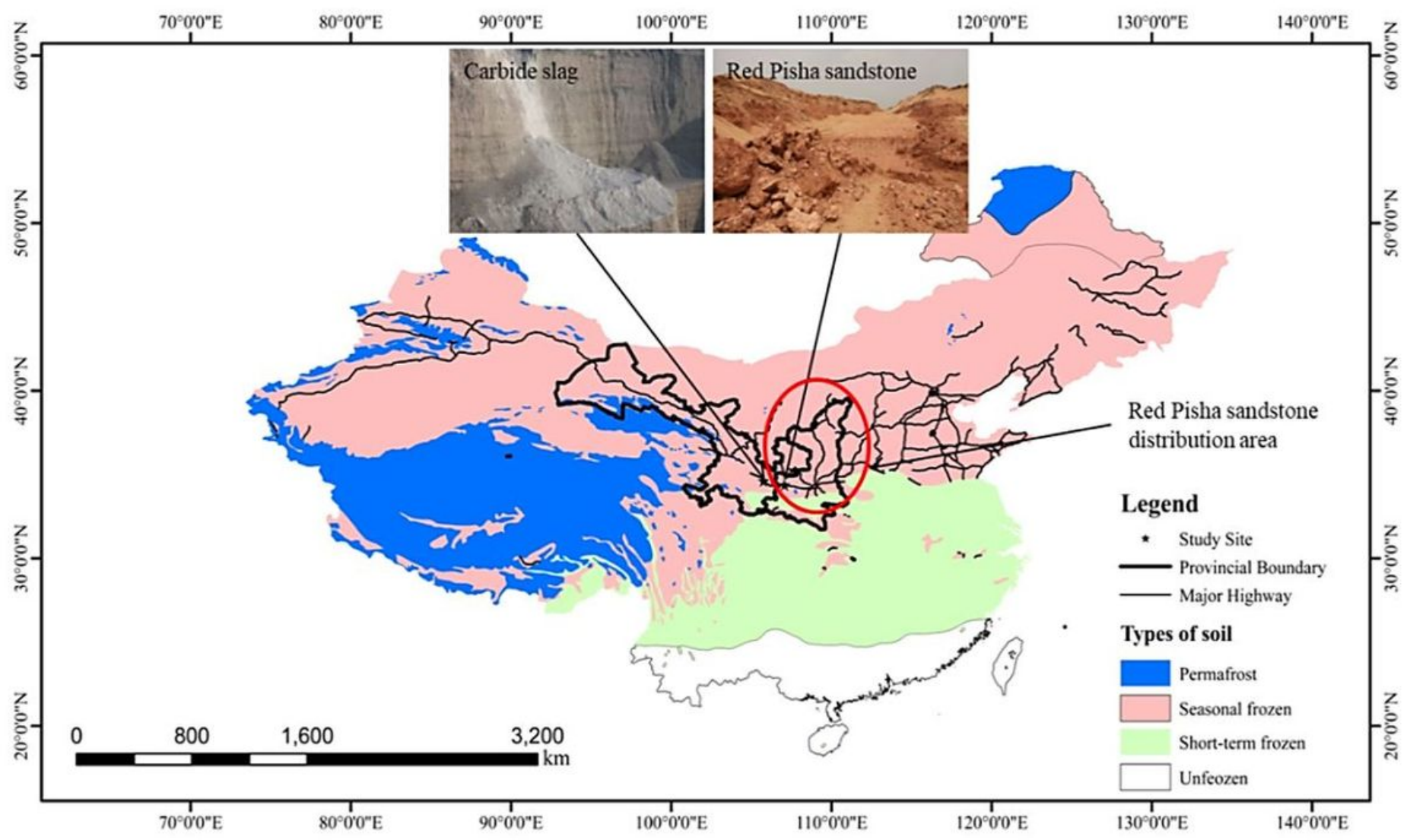

Figure 1

Location map of the study region
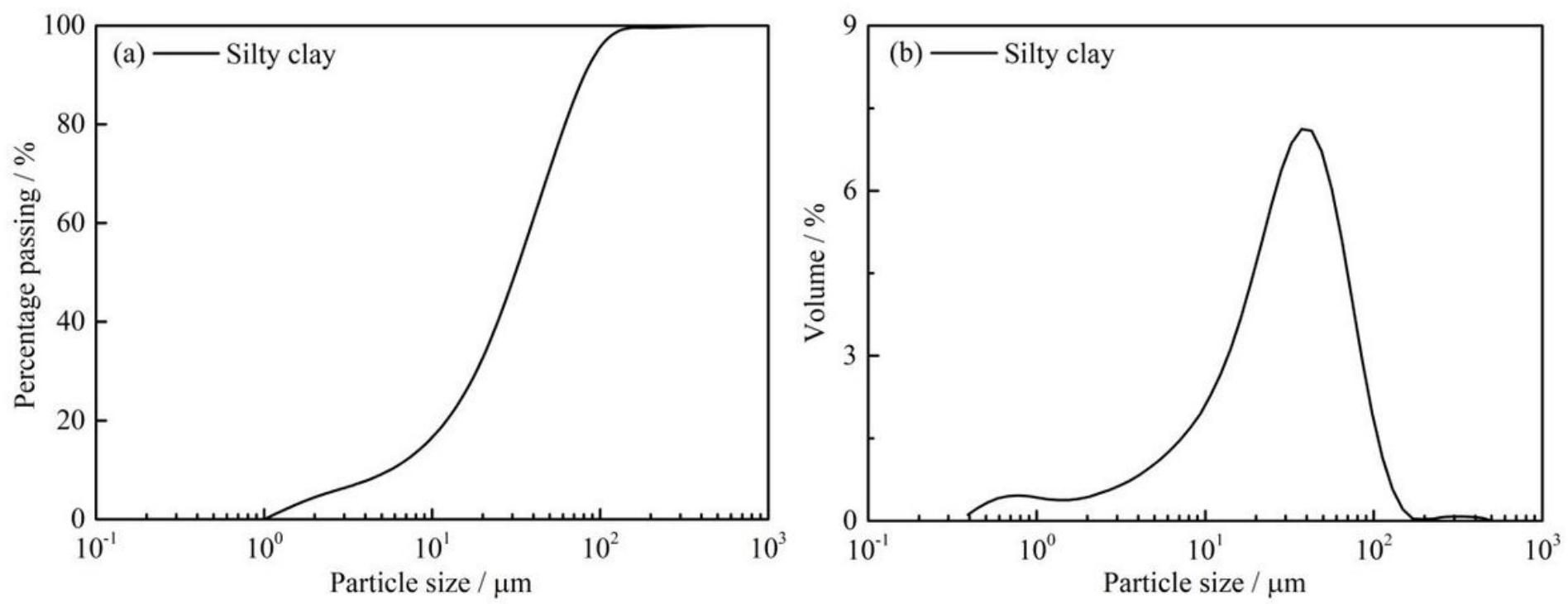

Figure 2

Particle size gradation curve of silty clay 


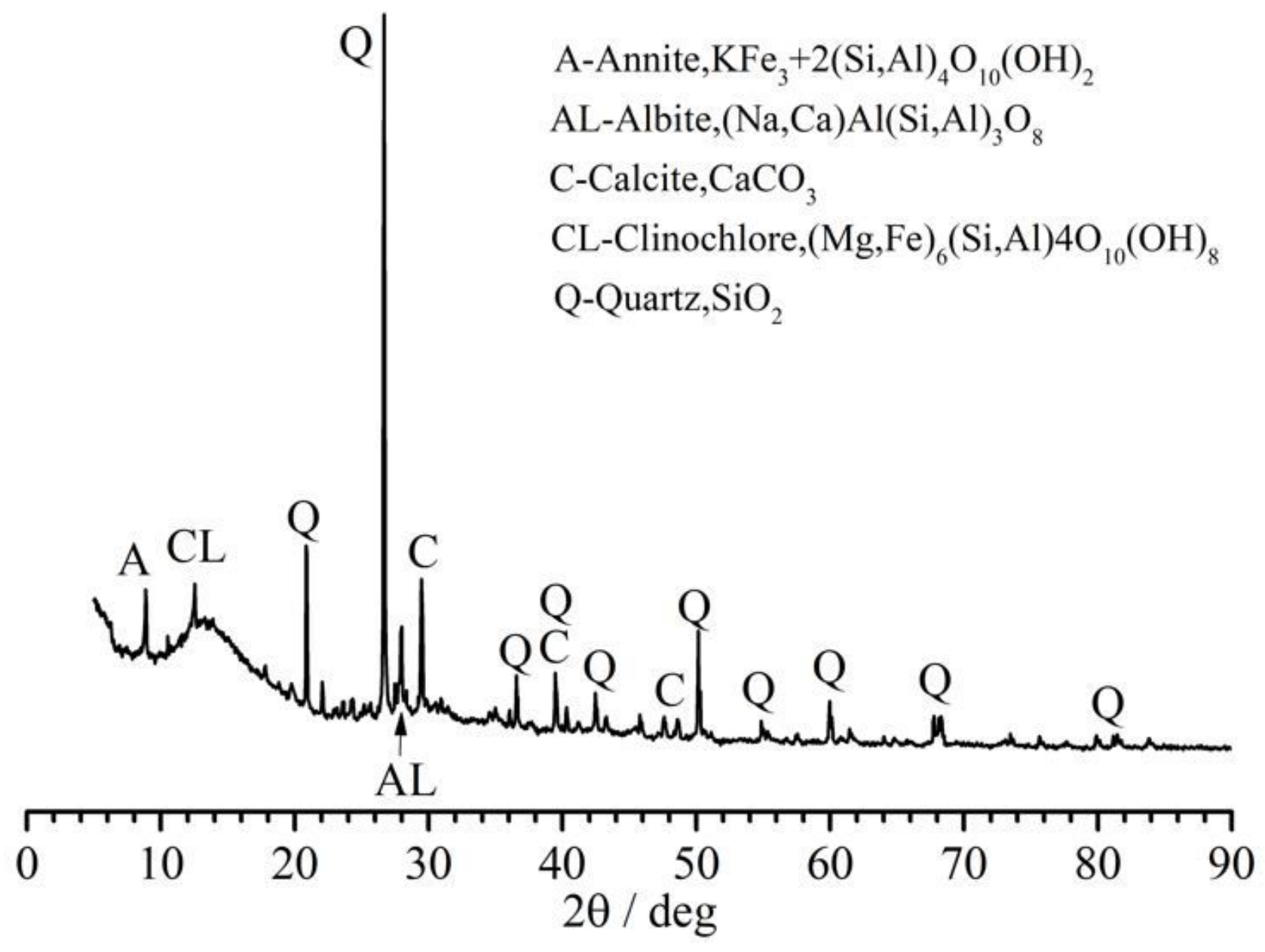

Figure 3

XRD patterns of silty clay
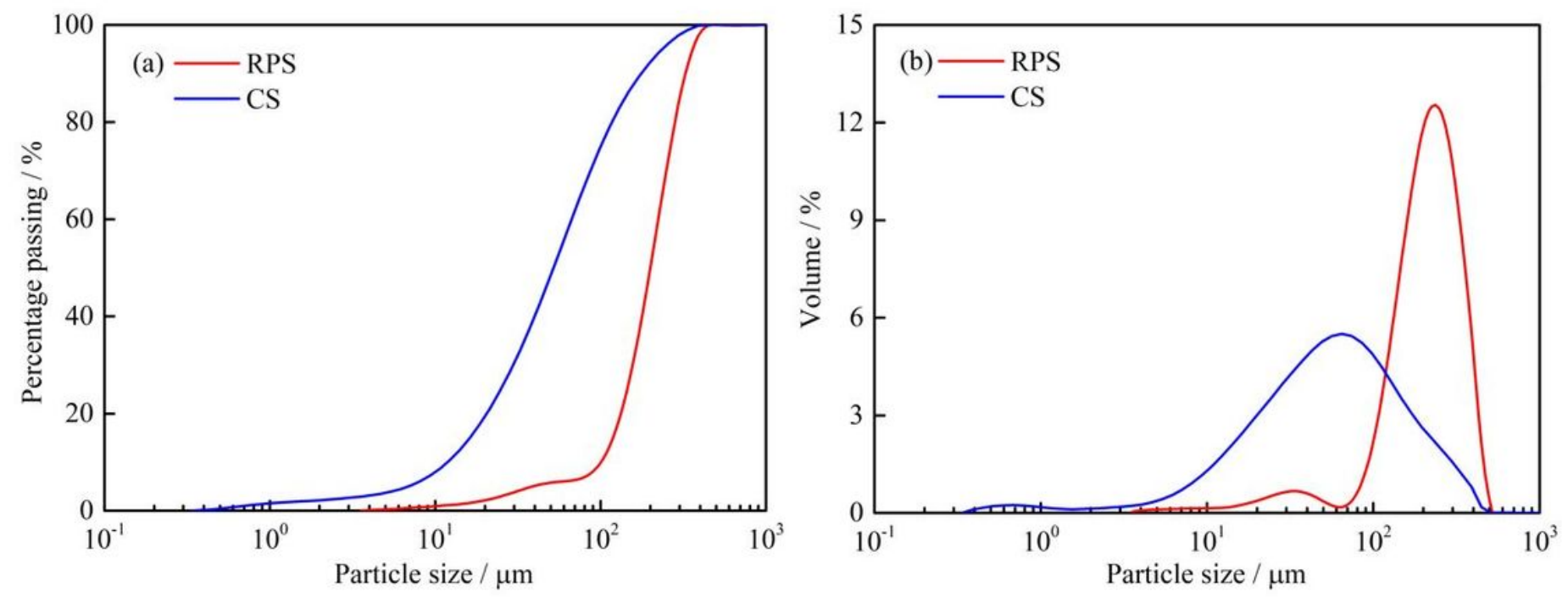

Figure 4 


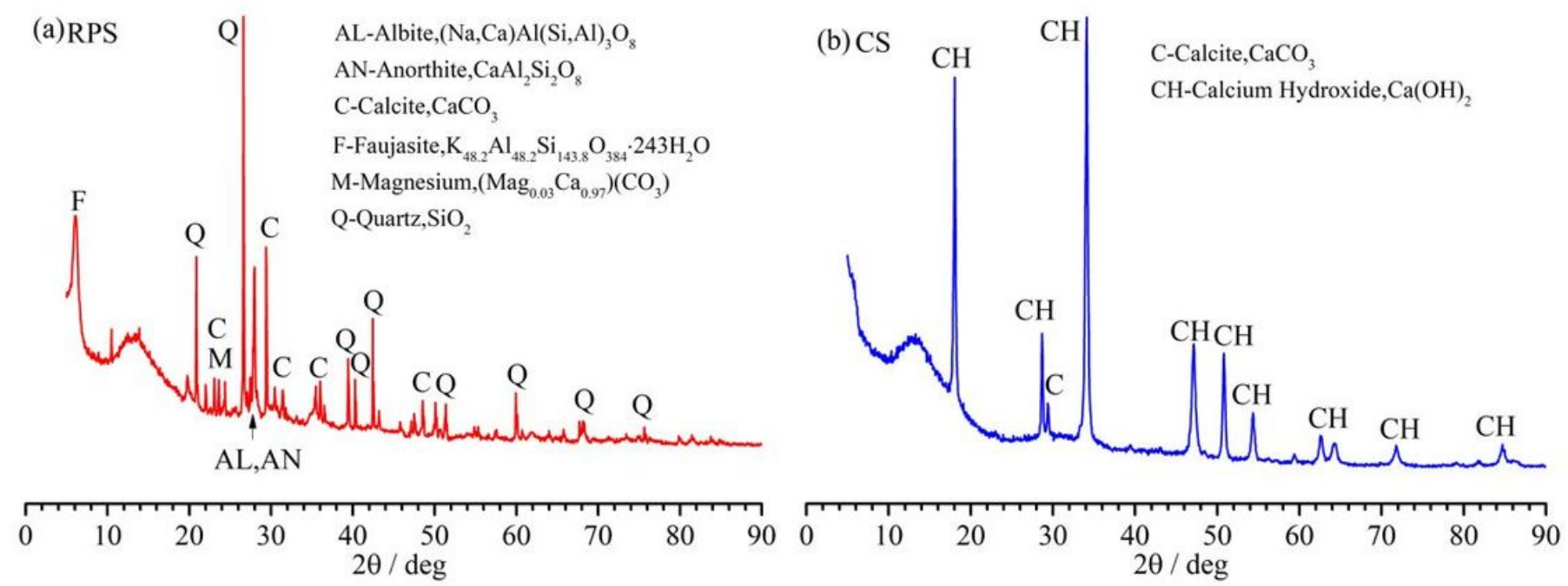

\section{Figure 5}

XRD patterns of RPS and CS

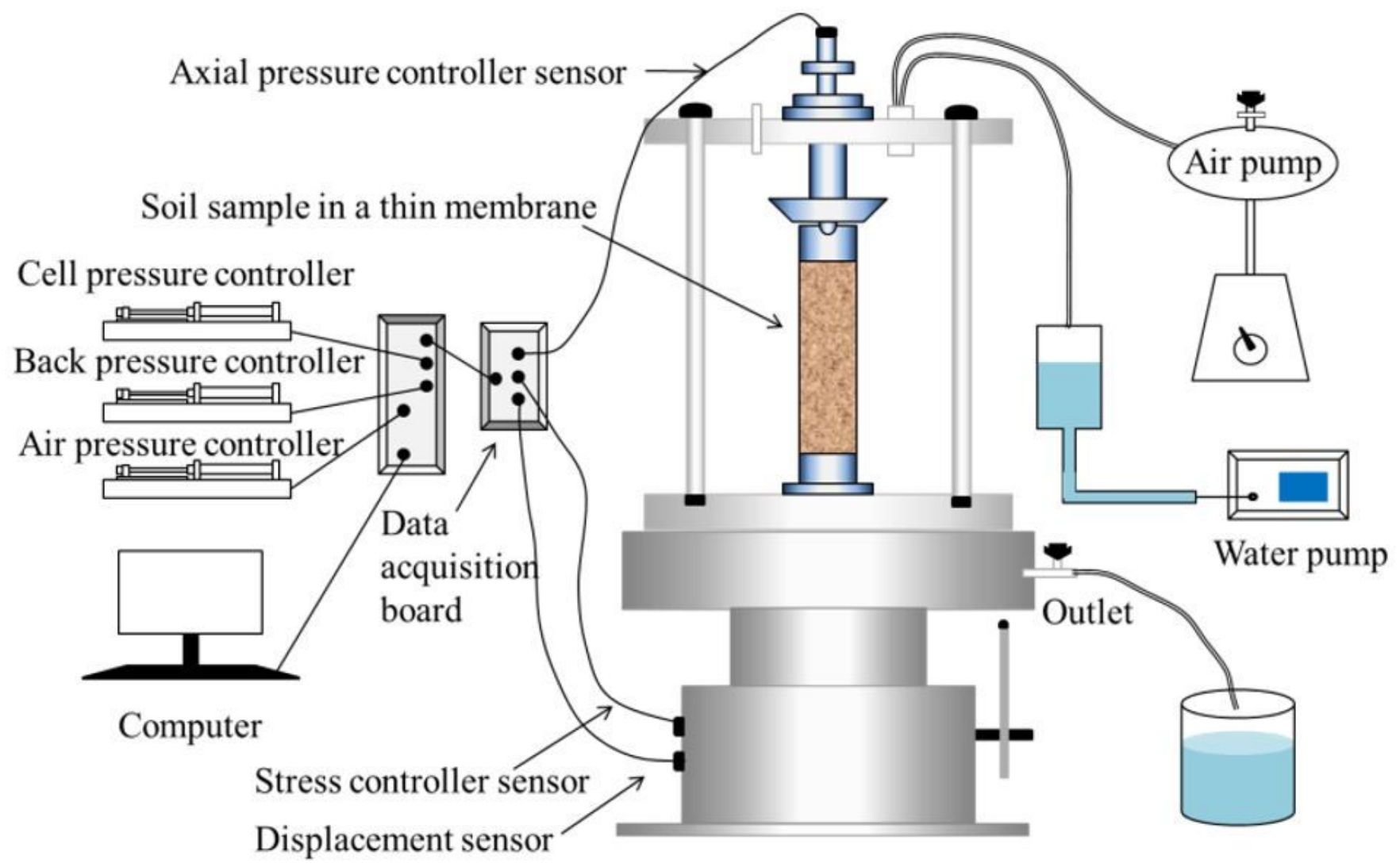

Figure 6 
Triaxial test equipment for GDS unsaturated soil
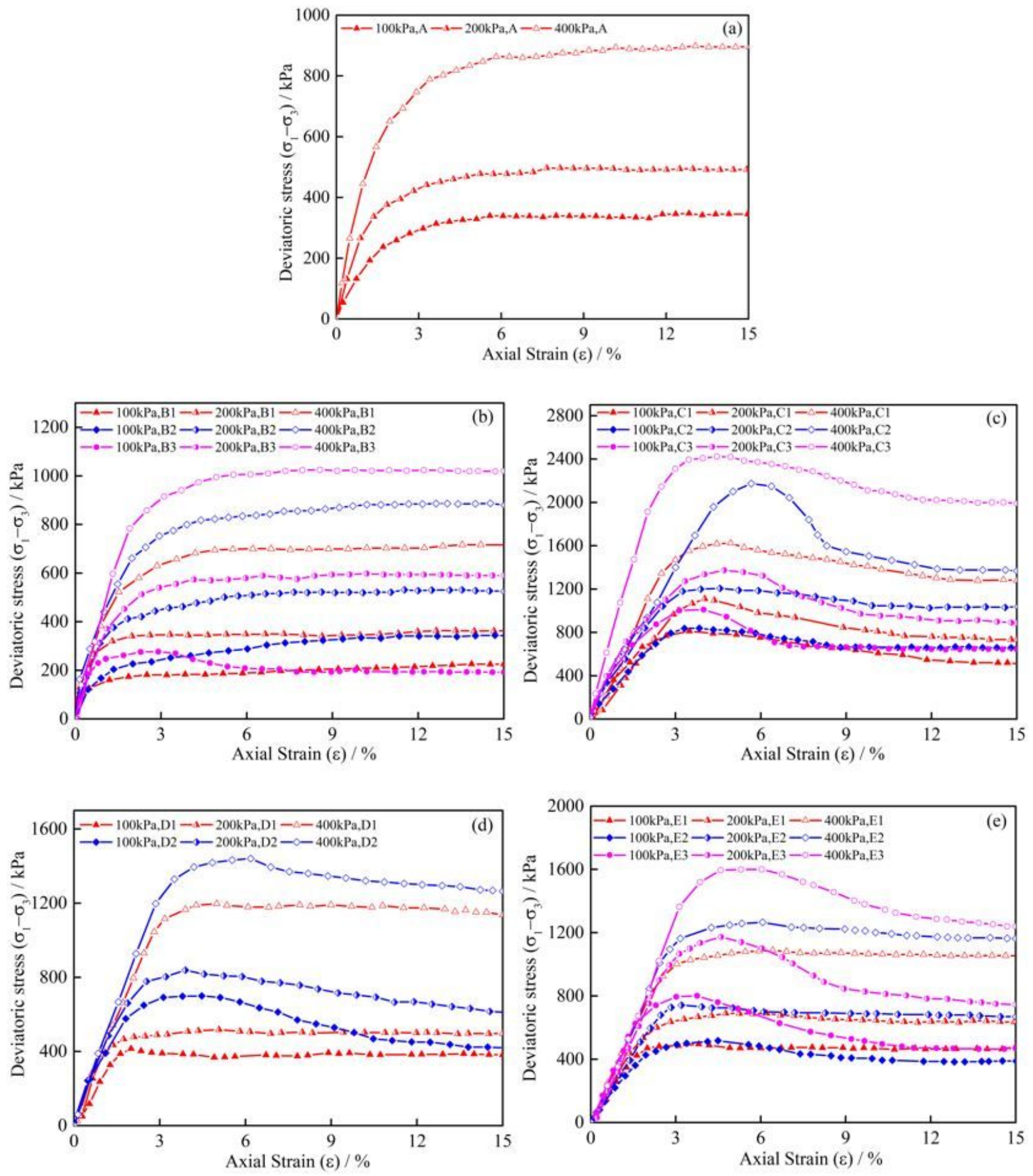

\section{Figure 7}

Deviatoric stress-strain curve under the influence of different confining pressure 

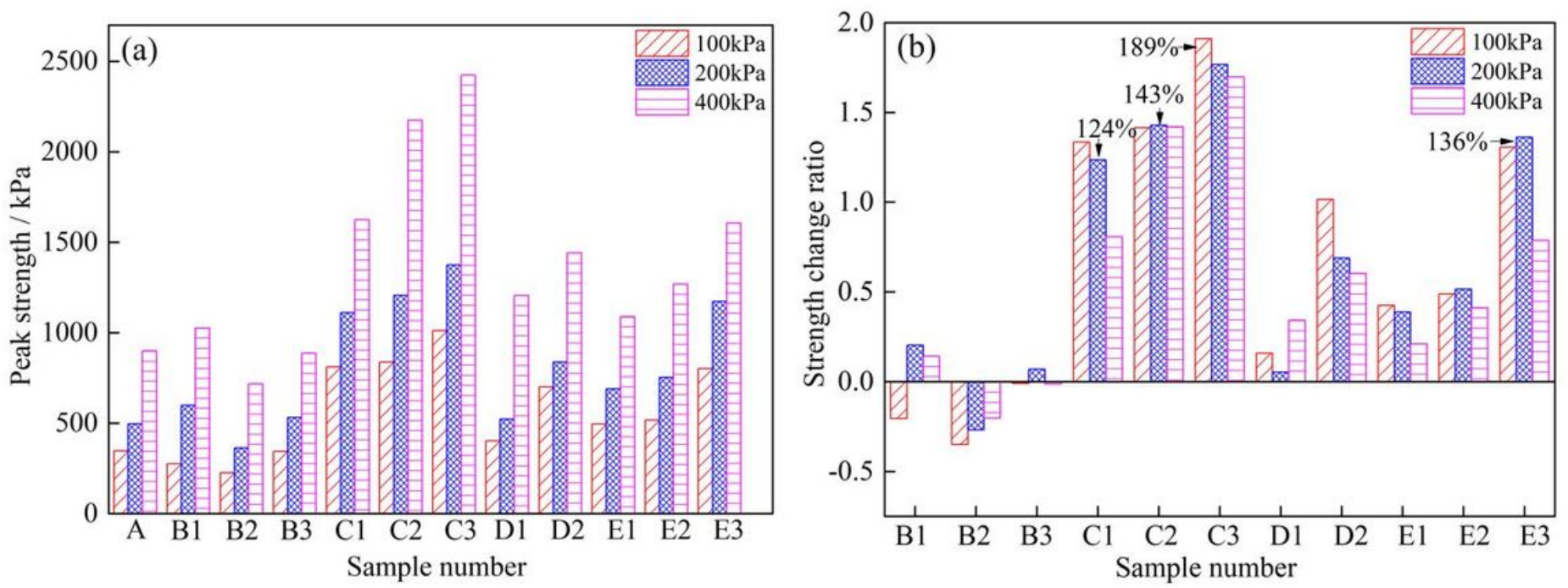

\section{Figure 8}

Diagram of the relationship between peak strength, strength change ratio, and admixture (c) Failure mode

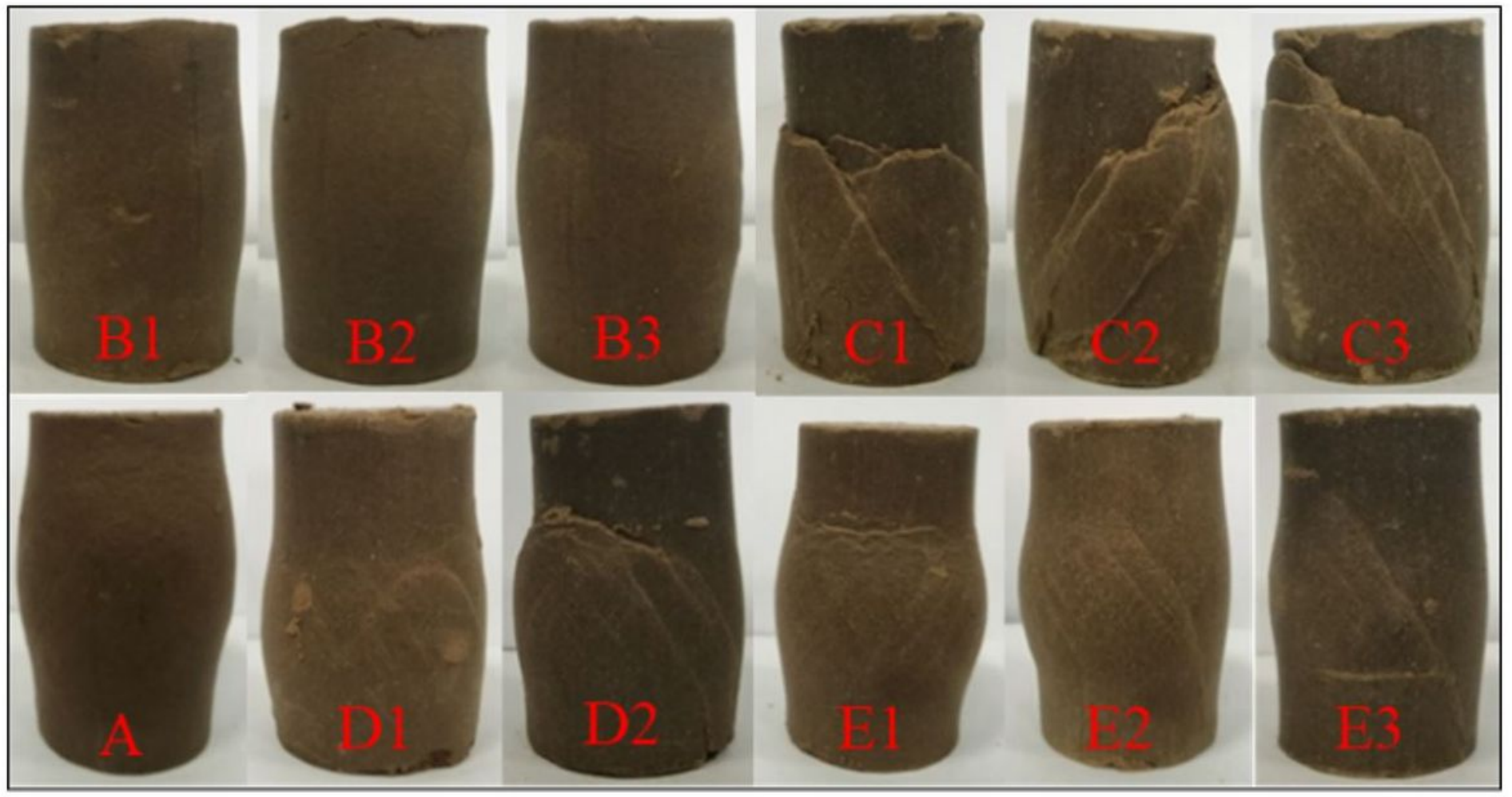

Figure 9

Failure mode of triaxial compression test 

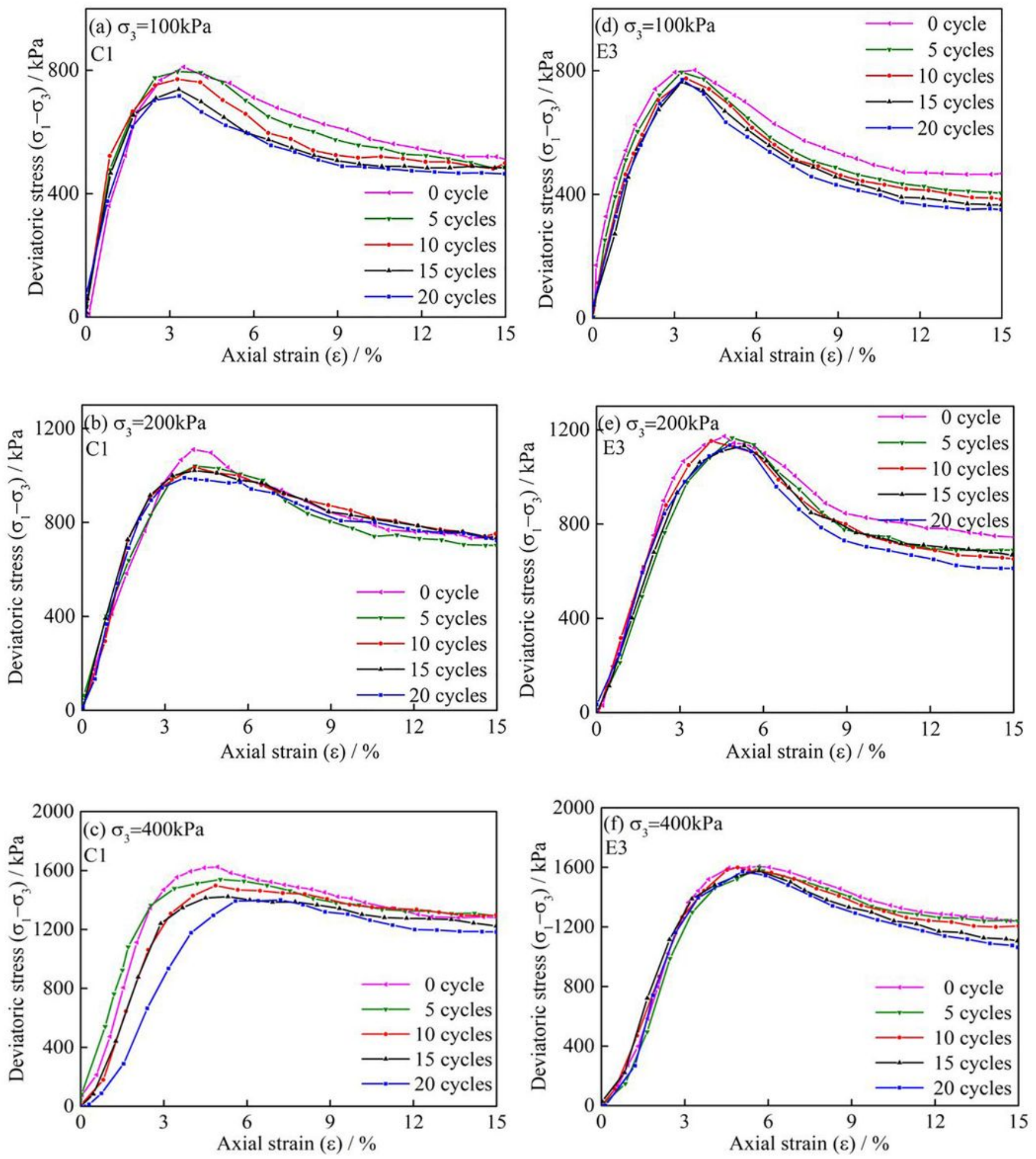

Figure 10

Stress-strain curve of triaxial compression tests under different confining pressure and freeze-thaw cycles. (a) $\mathrm{C} 1: \sigma 3=100 \mathrm{kPa}$ (b) $\mathrm{C} 1: \sigma 3=200 \mathrm{kPa}$ (c) $\mathrm{C} 1: \sigma 3=400 \mathrm{kPa}$ (d) $\mathrm{E} 3: \sigma 3=100 \mathrm{kPa}$ (e) $\mathrm{E} 3: \sigma 3=200 \mathrm{kPa}(\mathrm{f}$ ) $\mathrm{E} 3: 03=400 \mathrm{kPa}$ 

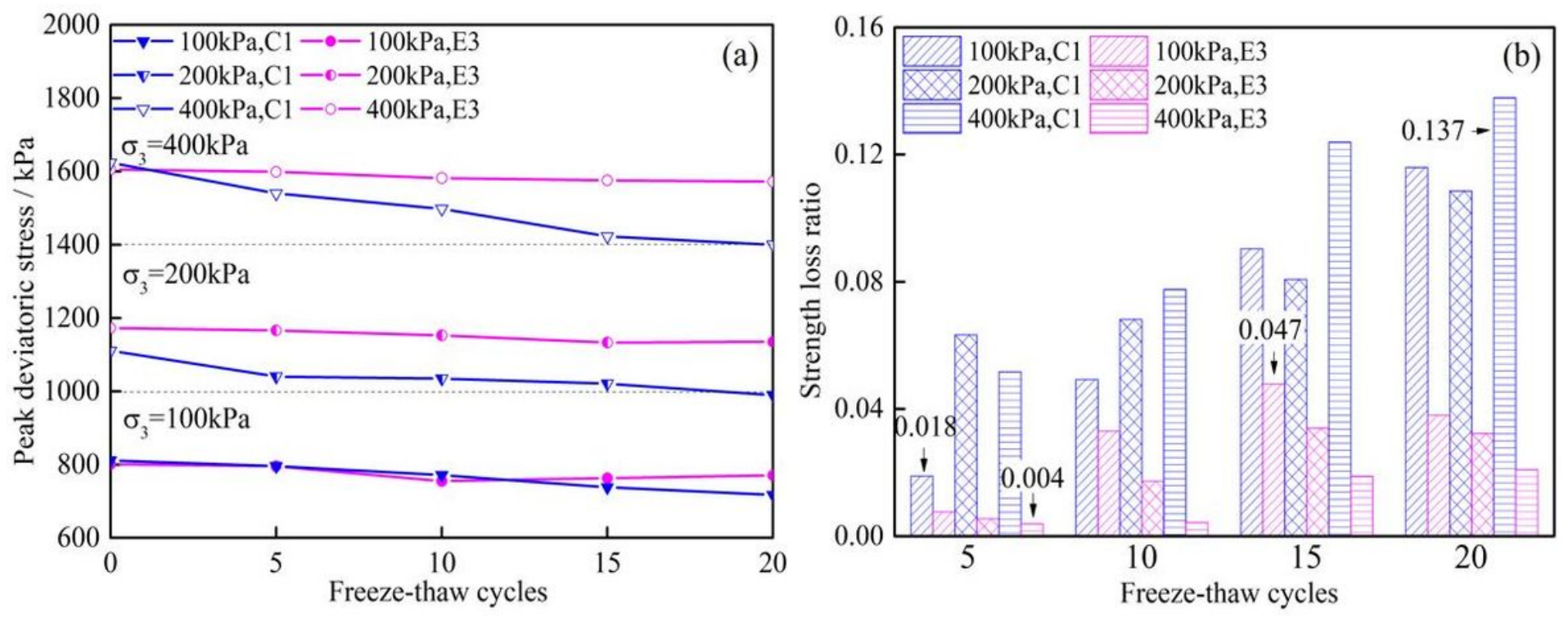

\section{Figure 11}

Chang of peak strength and strength loss ratio under different freeze-thaw cycles (b) Failure patterns of $\mathrm{C} 1$ and $\mathrm{E} 3$

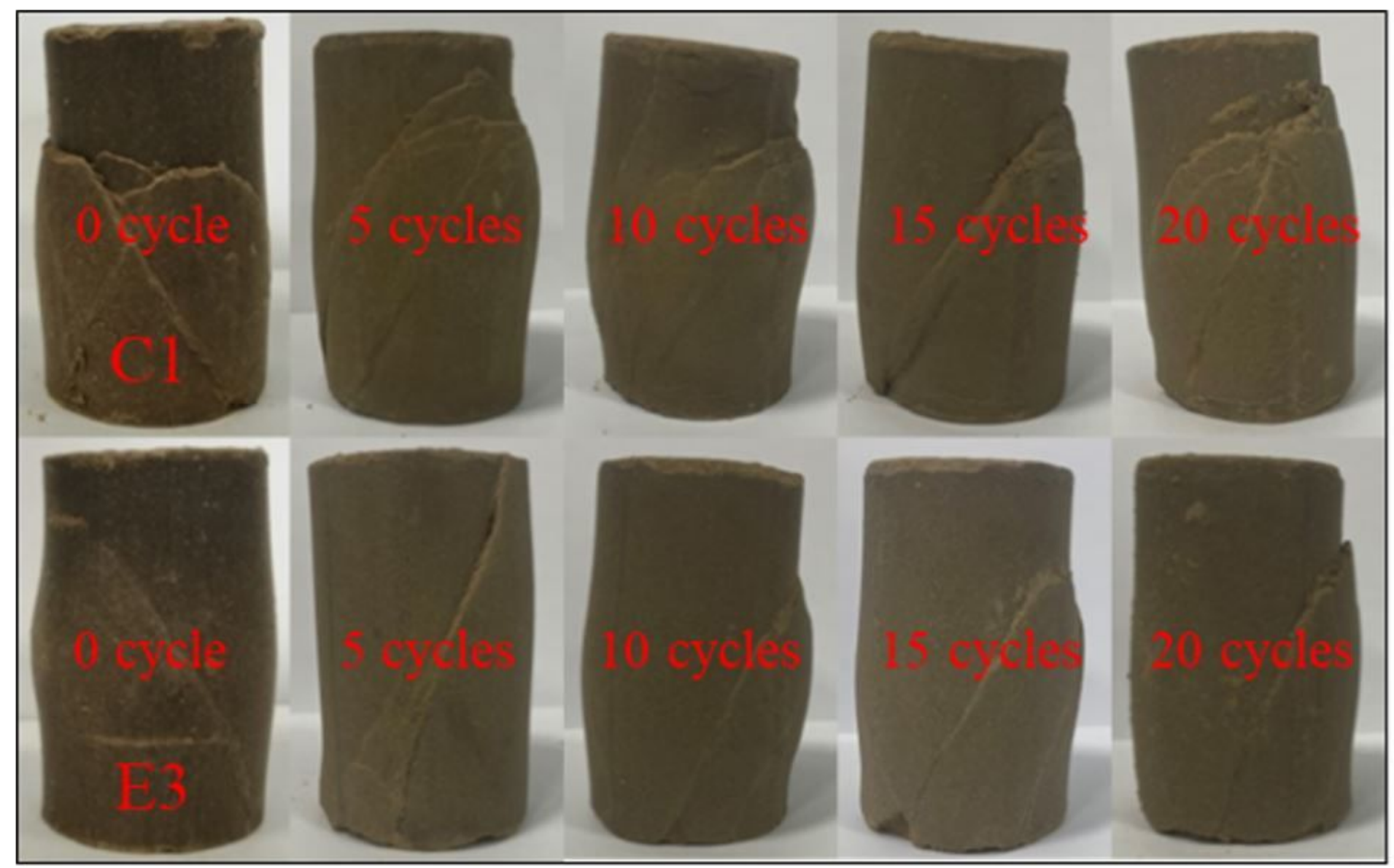

Figure 12 
Failure mode of triaxial compression test under different freeze-thaw cycles

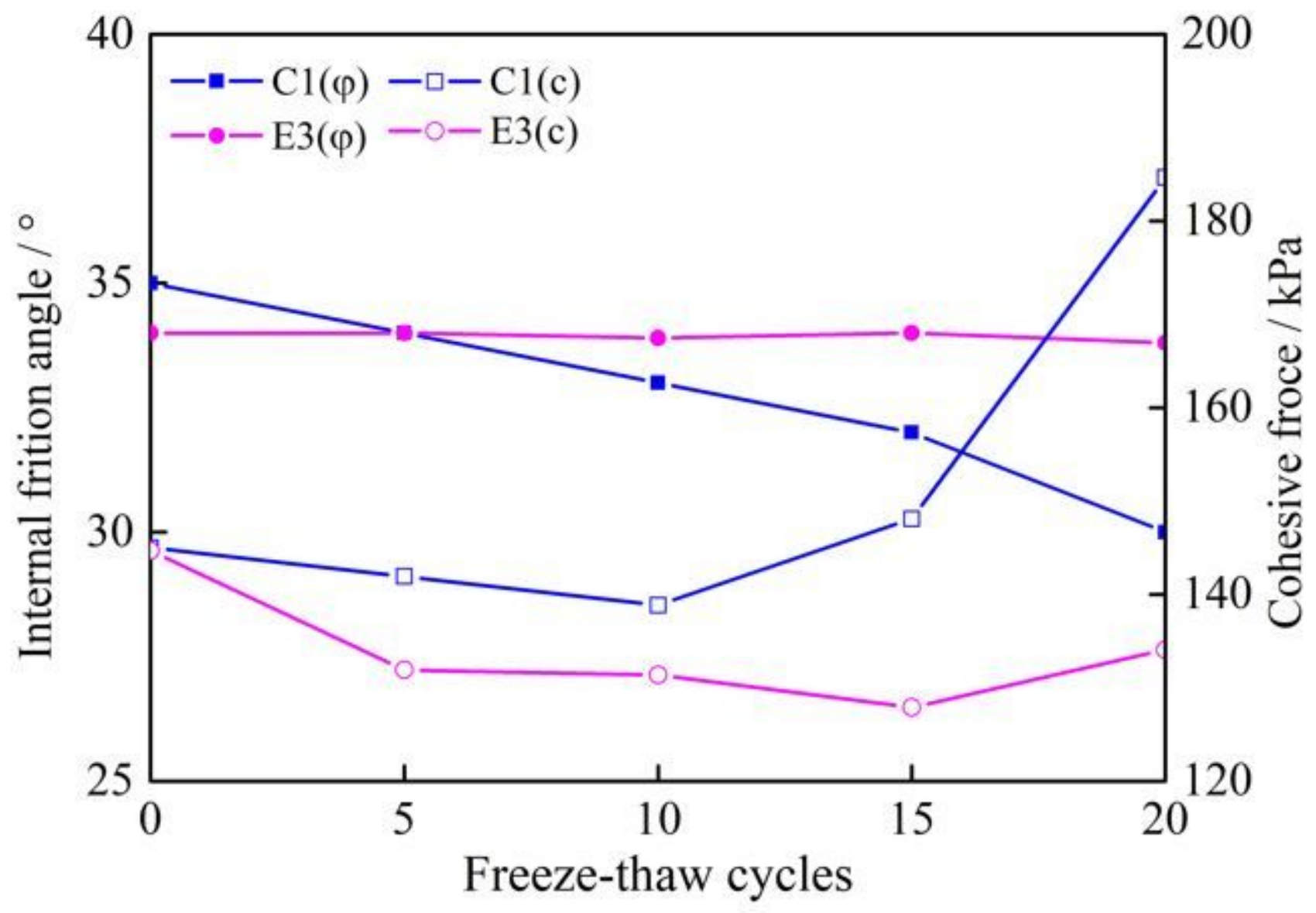

Figure 13

Chang of internal friction angle and cohesive force under different freeze-thaw cycles
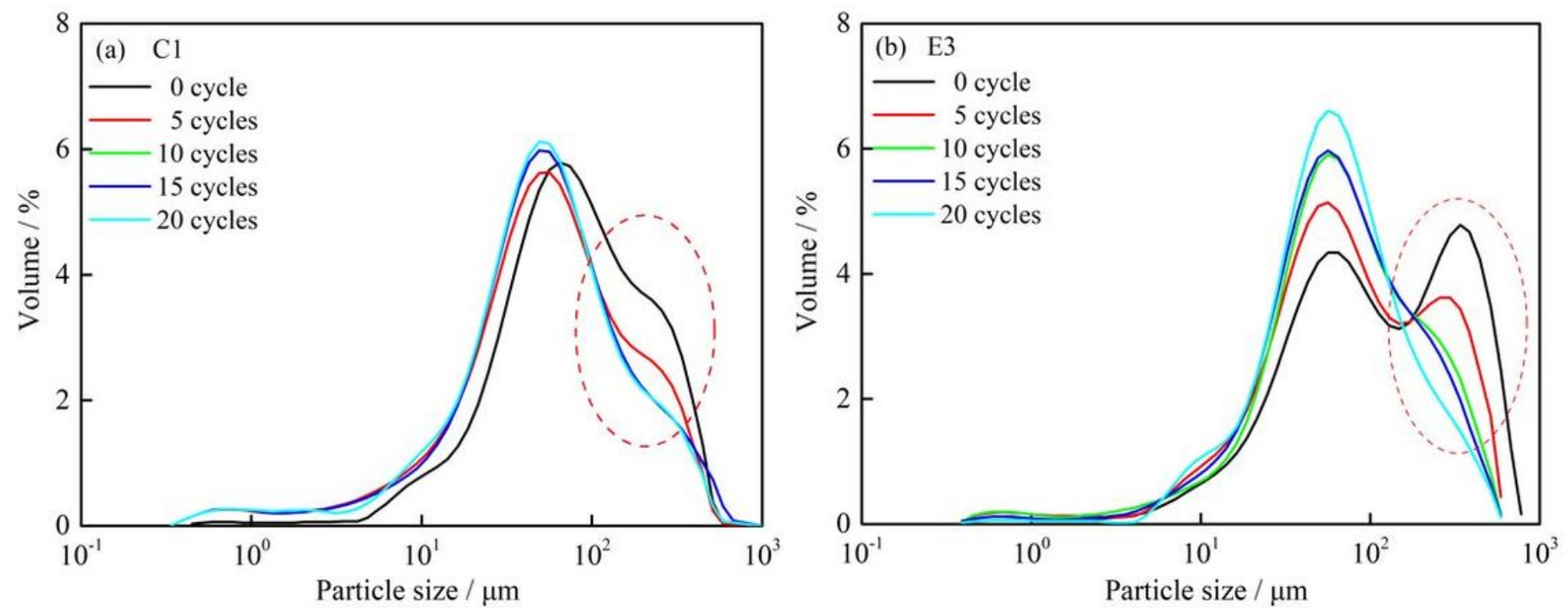

Figure 14 
Particle size gradation curve of $\mathrm{C} 1$ and $\mathrm{E} 3$ samples under different freeze-thaw cycles

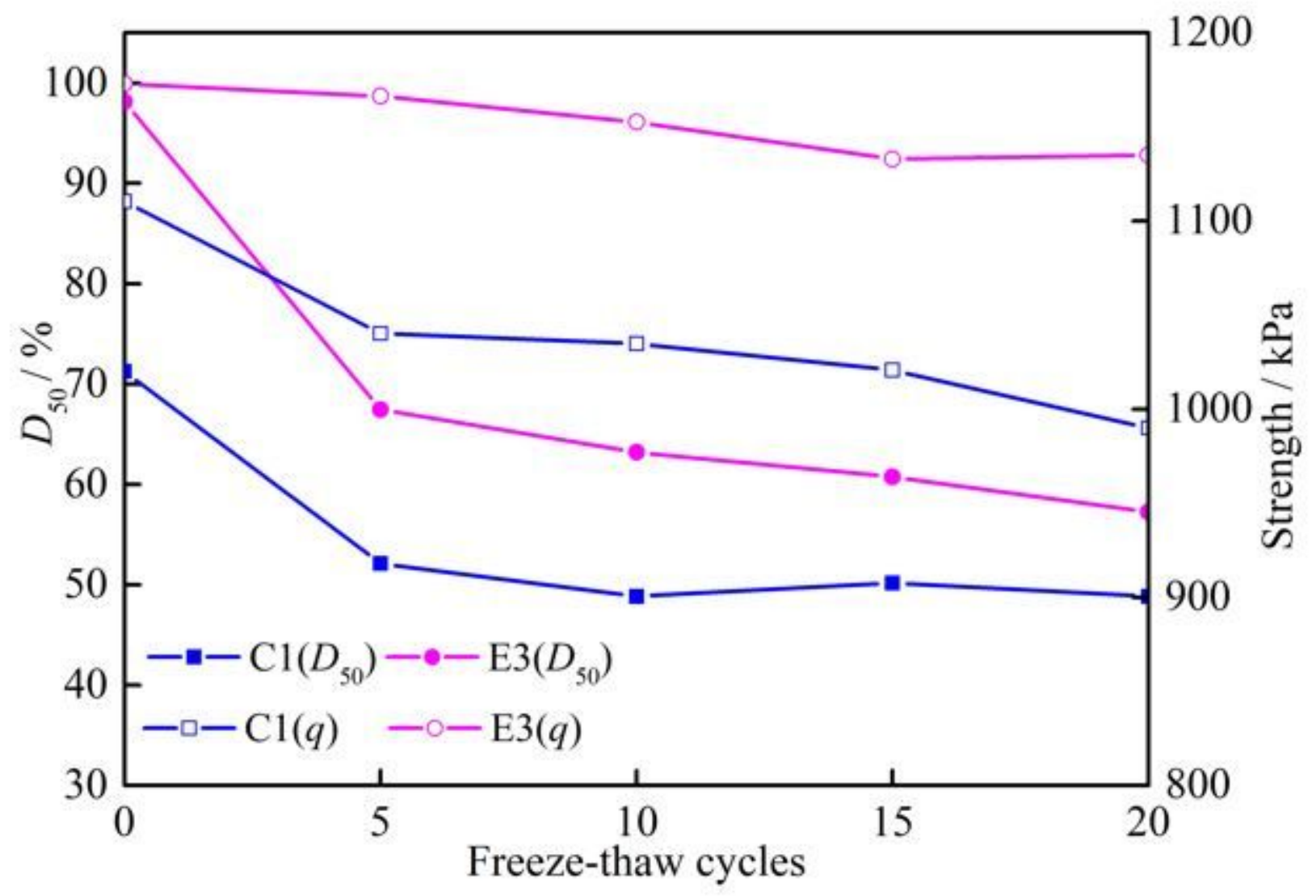

Figure 15

Correlation between strength and average particle size D50 of C1 and E3 under different freeze-thaw cycles 


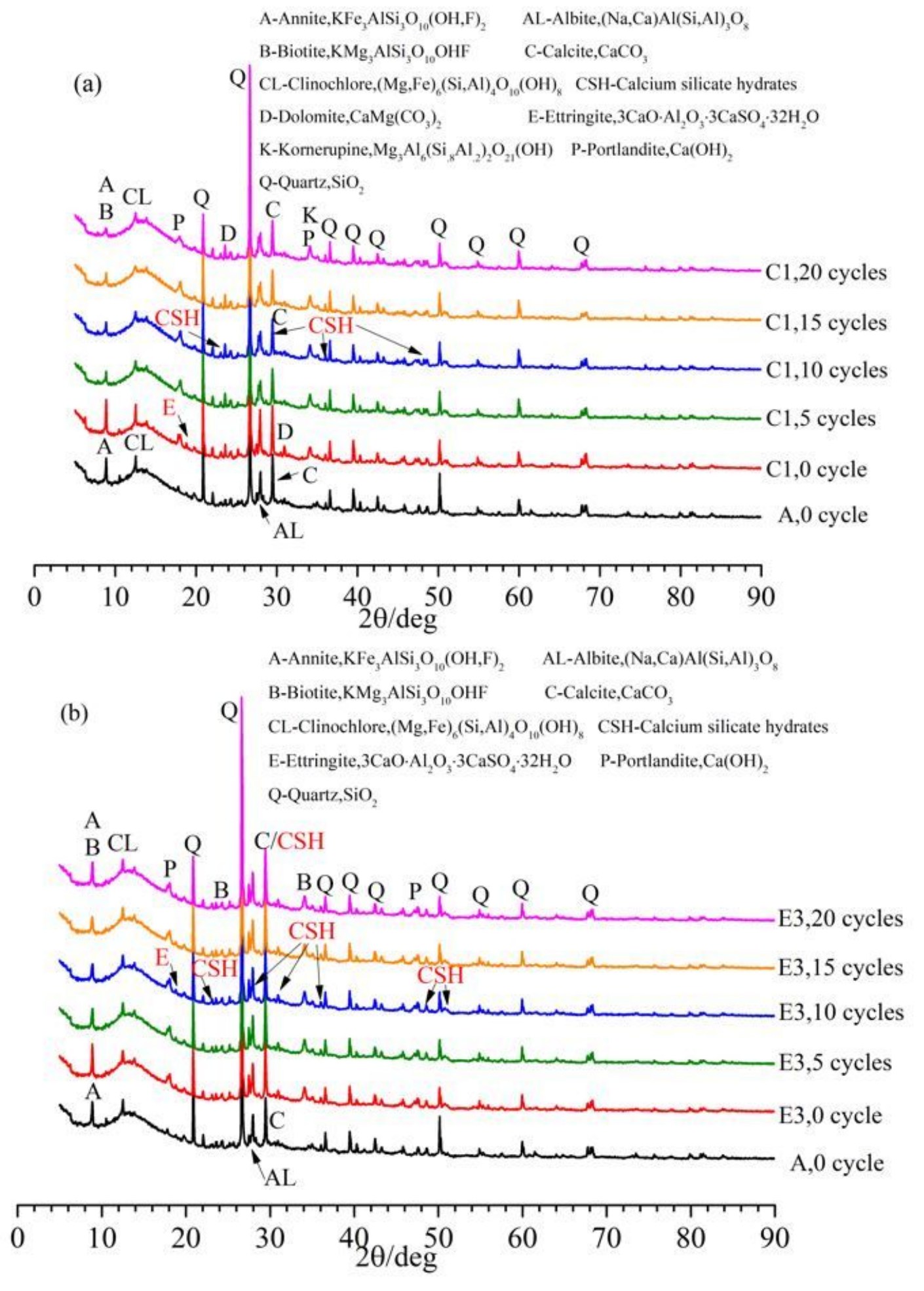

Figure 16

XRD patterns of $\mathrm{C} 1$ and $\mathrm{E} 3$ under different freeze-thaw cycles 


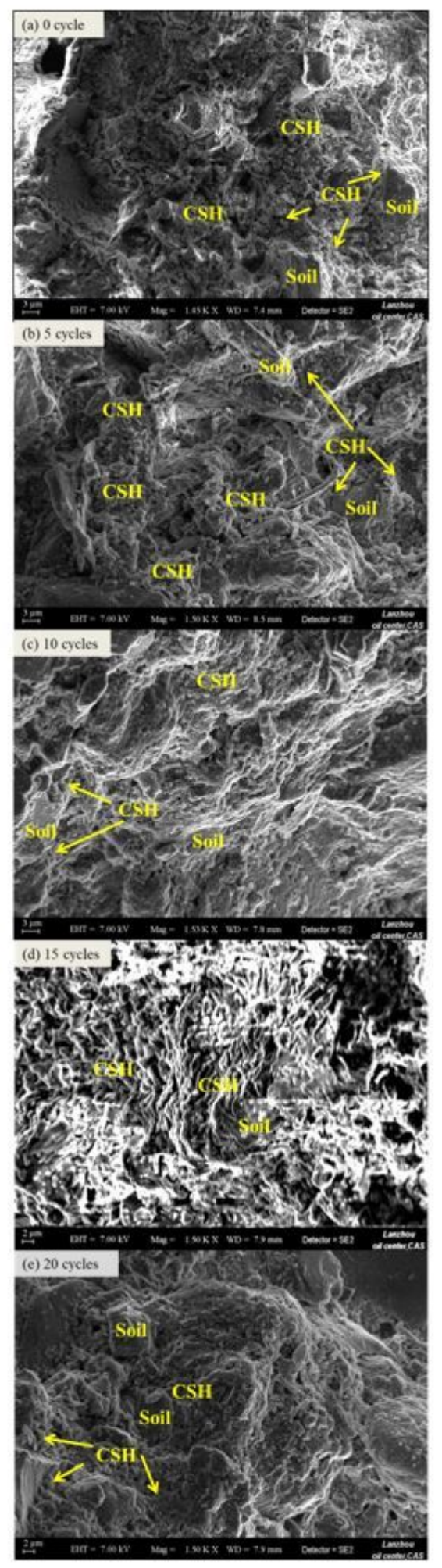

Figure 17

SEM images of $\mathrm{C} 1$ samples 


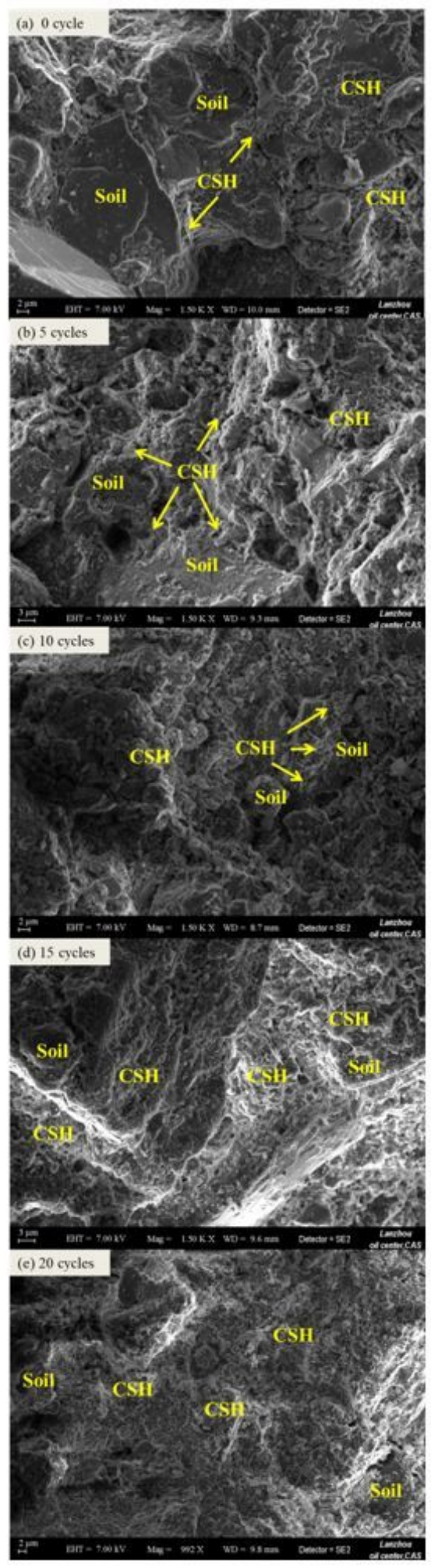

Figure 18

SEM images of E3 samples 